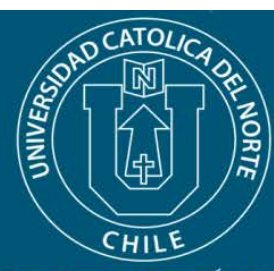

REVISTAS CIENTIIFICAS
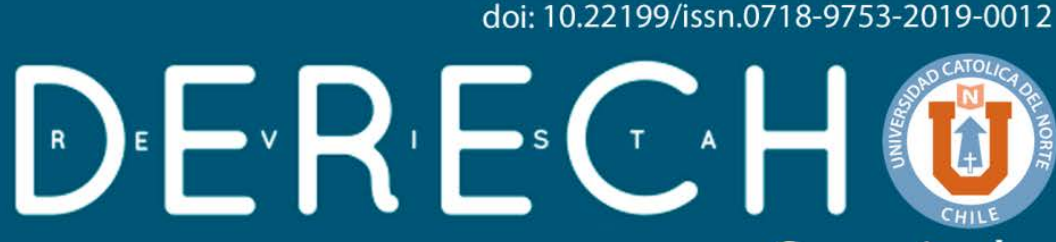

Co qu i m bo

ISSN: 0718-9753 (En línea)

\title{
Los procedimientos abreviados y simplificados y el riesgo de condenas erróneas en Chile: resultados de una investiga- ción empírica
}

\section{Abbreviated and simplified proceedings and the risk of wrongful convictions in Chile: findings from an empirical research}

\author{
Mauricio Duce Julio*(1) https://orcid.org/0000-0002-5068-926X \\ *Universidad Diego Portales, Santiago, Chile. Profesor. Mg. en Ciencias Jurídicas, U. Stanford. \\ (4) mauricio.duce@udp.cl \\ (cc) BY
}

Resumen:

La identificación, por medio de una investigación de corte empírico, la existencia de factores y dinámicas de funcionamiento de nuestro sistema de justicia penal que generen riesgos de condenas erróneas en el uso de los procedimientos abreviados y simplificados con reconocimientos de responsabilidad. Se pretende determinar si se presentan elementos que han sido descritos en la experiencia comparada como aquellos que incrementan la probabilidad de generar condenas erróneas. Los hallazgos indican que varios de estos se encuentran presentes en Chile y que, por lo mismo, podríamos estar en presencia de una situación más compleja que la que se tiene consciencia.

Palabras Clave: Procesos negociados; Condenas erróneas; Procedimiento abreviado; Procedimiento simplificado.

\begin{abstract}
:
Identify, through an empirical research, the presence of factors and dynamics of work in our criminal justice system which creates risks of wrongful convictions in the use of the abbreviated and simplified procedures with guilty pleading. I attempt to establish if some aspects depicted in the comparative experience as those increasing the likelihood of wrongful convictions are present in our reality. The main findings indicates that several of those elements are present in Chile and, therefore, the scenario could be more complex than we believe in this gard. Keywords: Plea bargaining; Wrongful convictions; Abbreviated procedure; Simplified procedure.
\end{abstract}


Los procedimientos abreviados y simplificados y el riesgo de condenas erróneas en Chile.

\section{Introducción}

Una de las innovaciones más relevantes introducidas en nuestra legislación procesal penal, acorde además con una tendencia a nivel de derecho comparado, ha sido la de incluir procedimientos especiales que operan sobre la base de reconocer un espacio de negociación y consenso entre fiscal e imputado ${ }^{1}$. En efecto, existen dos procedimientos en nuestro Código Procesal Penal (Ley 19.696, 2000) que descansan en la existencia de un acuerdo entre estos actores, normalmente producto de una negociación previa. Se trata del procedimiento abreviado y del simplificado en la hipótesis con admisión de responsabilidad del imputado².

La naturaleza consensual de ambos procedimientos no ha estado exenta de críticas y polémicas desde diversos puntos de vista, tanto en la doctrina nacional ${ }^{3}$ como de manera más general en el ámbito comparado ${ }^{4}$. Una de las más fuertes que se formulan, aun cuando paradójicamente menos estudiada en nuestro país, es el riesgo que este tipo de procedimientos genera en la condena de personas inocentes. Es decir, en la posibilidad de que personas que no han cometido un delito estén dispuestas a aceptar los hechos que se le imputan o admitir responsabilidad en los mismos, producto de diversos incentivos y dinámicas del sistema que lleven en definitiva a su condena. Este punto corresponde al foco central de este trabajo. Mi objetivo es identificar, por medio de una investigación de corte empírico, la existencia de factores y dinámicas de funcionamiento de nuestro sistema que generen riesgos de condenas erróneas en el uso de ambos procedimientos en Chile. Así, el trabajo presenta los resultados de una investigación cuyo objetivo central es el ofrecer una aproximación con base empírica de las dinámicas que se desarrollan en nuestro sistema de justicia penal en relación con ambos procedimientos (con foco en la Región Metropolitana). Complementando, de esta manera, la escasa evidencia existente en nuestro medio sobre la materia. La idea es identificar si en nuestra realidad se presentan algunos factores que según la experiencia comparada tendrían incidencia en generar condenas erróneas. Ello nos debiera servir a futuro para desarrollar estrategias orientadas a minimizar y prevenir los riesgos.

\footnotetext{
${ }^{1}$ Una investigación reciente en 90 países de todos los continentes da cuenta de un incremento sustancial de los procedimientos con renuncia a juicio desde el año 1990. Así, mientras antes del año 1990 sólo 19 países de ese universo contaban con esta posibilidad, al año 2016 esa cifra se había incrementado a 66. (Fair Trials, 2017, pp. 23-33). La literatura que describe los distintos tipos de procedimientos consensuales es amplísima. Un buen texto con trabajos que revisan la situación en países de tradiciones jurídicas diversas tales como Alemania, Argentina, Croacia, Dinamarca, Escocia, Estados Unidos, Francia, Holanda, Italia, Noruega, Polonia y el sistema de la Corte Penal Internacional en: Thaman (2010). Sobre el desarrollo de estos tipos de procedimientos en Europa puede verse: Albrecht (2001). Para el caso de América Latina puede revisarse Maier y Bovino (2001).

${ }^{2}$ Más adelante explicaré con algo más de detalle ambos procedimientos. Por ahora señalo que el abreviado se encuentra regulado en la Ley 19.696 (2000, art. 406 y ss.) y el simplificado en los art.388 y ss. La modalidad específica de procedimiento simplificado con reconocimiento de responsabilidad se regula en el art. 395 del mismo cuerpo legal.

${ }^{3}$ Para tener una visión panorámica de algunos de estos debates: Del Río Ferretti (2009), Riego Ramírez (2000) y Salas Astrain (2015, pp. 247-283).

${ }^{4}$ Nuevamente se está en presencia de un tema que ha sido objeto de enorme desarrollo en la literatura comparada y que resulta casi imposible resumir. Sólo para tomar dos ejemplos paradigmáticos de críticas formuladas desde distintas tradiciones jurídicas puede verse: Langbein (2001) y Ferrajoli (2001).
} 
Para estos efectos, el trabajo se basa en una investigación de orientación empírico-cualitativa y exploratoria que descansa en varias fuentes. En primer lugar, se ha realizado una revisión de los recursos de revisión resueltos por la Corte Suprema en el período 2007-2016 sobre casos generados por el sistema acusatorio. Luego se han sistematizado los relatos de la experiencia de un número importante de informantes expertos de nuestro sistema procesal penal, obtenidos por medio de entrevistas semiestructuradas efectuadas a un total de 36 actores del sistema de justicia penal de la Región Metropolitana, incluyendo a abogados privados (6), defensores penales públicos (8), fiscales del Ministerio Público (13) y jueces de garantía (9). Dichas entrevistas fueron realizadas entre los meses de mayo de 2015 y noviembre de $2016^{5}$. Esta metodología otorga mucha fortaleza a los hallazgos vinculados a la descripción de prácticas en las que estos observadores expertos son testigos calificados, especialmente cuando surgen patrones comunes y ellos son descritos por actores que cumplen roles institucionales diversos como es el caso. En cambio, tiene algunos límites en relación a las áreas en dónde se relatan percepciones u opiniones y no su experiencia directa. Por lo mismo, se ha hecho un esfuerzo de complementar la investigación con la utilización de otras fuentes.

Así, la investigación también ha recopilado estadísticas y datos provenientes de las instituciones del sistema, algunos publicados en diversos textos o sitios web de acceso general y otros obtenidos gracias a requerimientos de información específicos realizados por medio de solicitudes de transparencia en el curso del desarrollo de la investigación. Además, esta investigación ha sido complementada con un estudio empírico exploratorio basado en la observación de 103 audiencias (63 de procedimientos simplificados con aceptación de responsabilidad y 40 de procedimientos abreviado) efectuadas en tres tribunales de garantía de la ciudad de Santiago entre los meses de diciembre de 2016 y abril de 2017. Dicho trabajo ha sido elaborado por una tesista de magíster que fue dirigida por el autor de este texto y que contó con apoyo del Proyecto Fondecyt que da origen al mismo (Zagmut Venegas, 2017) ${ }^{6}$. Finalmente, se ha recurrido a otras fuentes secundarias disponibles en la materia en nuestro país.

Para el cumplimiento de sus objetivos, el trabajo se estructura, además de esta introducción, en dos capítulos y una sección final de conclusiones. En el primer

\footnotetext{
${ }^{5}$ En el Anexo de este trabajo se aportarán mayores detalles acerca de las características del universo entrevistado y contenidos de la entrevista, pero adelanto que se trató de personas con experiencia directa de trabajo cotidiano en el sistema e integrado por un $36,1 \%$ de mujeres y un $63,8 \%$ de hombres. Todos los entrevistados serán citados en género masculino y con un número asignado por rol que desempeñan y la fecha de la entrevista, todo esto con el propósito de salvaguardar su anonimato. Cuando se reproduzcan los contenidos de las entrevistas se lo hará en el lenguaje textual formulado por cada entrevistado de manera de no afectar el sentido de lo que quiso expresar, aun cuando en algunas ocasiones eso lleve a un uso de lenguaje coloquial producto del nivel de confianza adquirida en el desarrollo de la entrevista.

${ }^{6}$ Aprobada con nota final 6,8. Las audiencias fueron observadas en el $4^{\circ}, 7^{\circ}$ y $12^{\circ}$ Juzgados de Garantía de Santiago entre el 28 de diciembre de 2016 y el 5 de abril de 2017. La selección de estos tres juzgados estuvo orientada a conocer el trabajo en jurisdicciones que cubren comunas de distinto nivel socio-económico. Como ya se señaló, no se trata de un estudio empírico que pretenda tener representatividad sino más bien un alcance exploratorio en un contexto en el que casi no existe evidencia en Chile en la materia. Una descripción detallada de la metodología empleada puede verse en el anexo del trabajo citado, páginas 96 a 98.
} 
capítulo presento brevemente información del ámbito comparado que da cuenta del impacto que tienen este tipo de procedimientos basados en el consenso y la negociación en la condena de inocentes, especialmente cuando se trata de figuras delictuales de gravedad mediana o baja. Esta información permitirá contar con un marco básico para contrastar con la situación en nuestro país. En la segunda sección analizo la realidad nacional, mostrando tanto datos empíricos sobre la relevancia de estos procedimientos como los principales hallazgos de la investigación. En la sección destinada a las conclusiones presento una breve reflexión final. Lo anterior se complementa con un anexo metodológico en el que se entregan mayores detalles de las entrevistas realizadas.

\section{Los procedimientos consensuales y la condena de inocentes en el ámbito comparado}

Los procedimientos consensuales operan regularmente sobre la base de la confesión del imputado de los hechos que se le imputan (reconoce los hechos o la responsabilidad en sus distintas variantes procesales nacionales) a cambio de asegurar, como contraprestación, un cierto resultado ofrecido por el fiscal. A partir de la confesión, el sistema está en condiciones de dictar una sentencia sin necesidad de realizar una audiencia de juicio. Dicha sentencia será normalmente condenatoria ya que en la base de estos procedimientos está la idea que el consenso suprime la necesidad de presentar prueba (por ello no es necesario realizar una audiencia de juicio para dictarla) y, por lo mismo, se exige muy poca evidencia adicional e incluso en algunos casos ninguna para llegar a tal resultado. En esta lógica, los jueces tienen escaso poder de control de la evidencia o antecedentes efectivamente disponibles en el caso. Esto genera el riesgo que sean procedimientos muy vulnerables a la posibilidad de tomar decisiones erradas si es que la confesión prestada por el imputado fue falsa ${ }^{7}$.

\subsection{El problema general}

La evidencia empírica muestra, desde hace algún tiempo, que los sistemas de justicia criminal trabajan regularmente con un número importante de confesiones falsas que generan un claro riesgo de condenas de inocentes quienes, por diversos motivos, están dispuestos a reconocer como propio un hecho que no cometieron. Las razones y contextos en que se producen estas confesiones de inocentes son diversas $^{8}$. Con todo, un caso en donde esto ocurre es precisamente en los procedimientos consensuales.

Un ejemplo de este fenómeno es lo que ocurre con el uso del plea bargaining en los Estados Unidos. En dicho país se suele señalar que alrededor de un $95 \%$ de las sentencias dictadas en los tribunales provienen de procesos llevados adelante bajo

\footnotetext{
${ }^{7}$ En esta dirección, véase, Roach (2010, p. 396).

8 Un excelente resumen de la investigación sobre la materia con aportes de evidencia empírica propios pueden verse en: Leo (2009, pp. 248-268). Desde la literatura en psicología, véase, Kasin (2005).
} 
esa modalidad ${ }^{9}$. El plea bargaining puede ser comprendido como la facultad de que disponen los fiscales para realizar negociaciones o concesiones con el objetivo de obtener admisión de responsabilidad por parte del imputado (guilty plea) ${ }^{10}$ que habilite a dictar una sentencia sin juicio previo ${ }^{11}$.

Más allá de la discusión teórica acerca de los problemas de esta institución, hoy la evidencia muestra de que se trata de un factor que aumenta la probabilidad de condenas de inocentes de manera significativa. Según datos disponibles en dicho país, un $11 \%$ del total de exoneraciones obtenidas gracias a ADN (350 casos) se habrían producido en procedimientos en donde el imputado se declaró culpable (Innocence Project, 2018). Según las cifras que contiene el National Registry of Exonerations (NRE), que elabora una base de datos del total de exoneraciones producidas en los Estados Unidos con y sin ADN, desde el año 1989 a la fecha, la situación sería algo peor. En efecto, a diciembre de 2017 dicho registro contabilizaba un total de 392 casos de exoneración de personas inocentes que se habían declarado culpables de un total de 2.134 casos registrados, es decir, un 18,4\% del total (University of California Irvine, \& University of Michigan, 2012). Las cifras muestran también que se trata de un problema que se estaría incrementando en los últimos años de manera significativa. Así, en el reporte de la institución que analizó el total de exoneraciones acumuladas entre los años 1989 y 2012 se identificó que en 71 de 873 casos (un 8,1\%) hubo una declaración de culpabilidad del imputado (Gross y Shaffer, 2012, p. 66). Al año 2016 esa cifra se había elevado a 74 de 166 casos exonerados (44,5\%) (The National Registry of Exonerations, 2017, p.1), siguiendo así una tendencia a un fuerte incremento desde el año $2013^{12}$.

Estas cifras en todo caso sólo representarían la punta del iceberg del problema real, debido a las dificultades prácticas de impugnar condenas en las que previamente existió una declaración de culpabilidad del propio imputado (Dripps, 2016, p. 1362). A pesar de esto, la importancia que han adquirido las declaraciones de culpabilidad de personas en los Estados Unidos que luego son exoneradas al acreditarse su inocencia ha generado desde hace tiempo una crítica desde el mundo académi$\mathrm{Co}^{13}$, pero también un nuevo movimiento de la sociedad civil que recientemente ha desarrollado una campaña de alto perfil público haciendo un llamado "to fix America's guilty plea problem" (a arreglar el problema de la declaración de culpabilidad de

\footnotetext{
${ }^{9}$ Estadísticas oficiales producidas entre los años fiscales 2012 y 2016 para el sistema federal muestran un promedio algo superior al $97 \%$ del total de sentencias en el período. Véase,(United States Sentencing Commission, 2018).

${ }^{10}$ El diccionario Black's Law (Garner, 2014) define al guilty plea como "Admisión formal que hace el imputado en el tribunal sobre su culpabilidad en un acto criminal que se le imputa en la medida que sea prestado con conocimiento y en forma voluntaria" (N.R.: traducción del autor).

${ }^{11}$ Existe una extensa literatura sobre el plea bargaining que resulta imposible resumir. Una visión histórica y de carácter general de la institución puede verse en Fischer (2004). Un análisis del plea bargaining como factor de condenas de inocentes puede verse en: Medwed (2012, pp. 52-68). Para una breve explicación en castellano con mucha información de contexto sobre la forma en que se lleva adelante la persecución penal en los Estados Unidos, el autor recomienda el trabajo de: Bovino (1997, pp. 65-71).

${ }^{12}$ El 2013 la cifra fue 15 de las 87 exoneraciones del año (17\% del total), lo que constituyó un record a esa fecha. The National Registry of Exonerations (2014, p. 1), el año 2015 dicha cifra subió significativamente a 65 de 149 casos $(43,6 \%)$ de condenas erróneas detectadas. The National Registry of Exonerations (2016, p. 1).

${ }^{13}$ Entre muchos, por ejemplo, véase: Blume y Helm (2014).
} 
los Estados Unidos). Dicho movimiento se plantea como propósito central visibilizar la dimensión del problema, para luego avanzar en algunas propuestas de solución. Ellos resumen el problema identificando cuatro factores o incentivos que operarían en conjunto y que explicarían su producción: fiscales que amenazan con el uso de la penas altas a los imputados si no se declaran culpables (en el caso extremo con el uso de la pena de muerte); la existencia de diversos incentivos al imputado inocente para declararse culpable transformando ésta en "la opción más racional" disponible; abogados defensores que entregan consejos inadecuados a sus representados; $y$, jueces que fallan en su rol de control de las declaraciones de culpabilidad, lo que permite a un sistema sobrecargado de trabajo funcionar ${ }^{14}$.

Estos factores coinciden en parte con aquellos que más detalladamente ha identificado la literatura especializada disponible. Así, Bibas (2014, pp. 158-160), quien en su trabajo hace un resumen del estado del arte en la materia, ha destacado también los incentivos perversos que tienen fiscales, jueces y defensores para promover declaraciones de culpabilidad, agregando a ello el impacto que produce el trabajo policial. A esto suma también un conjunto de elementos estructurales del diseño y funcionamiento práctico de los procesos penales de los Estados Unidos que incorporan presiones adicionales a los imputados que promueven las declaraciones de culpabilidad. Por ejemplo, el uso de la prisión preventiva y la privación de libertad; problemas en el cumplimiento de las reglas de descubrimiento de la evidencia que dispone la persecución penal; la existencia de reglas que permiten a los imputados declararse culpables y ser condenados como tales, pero a su vez manteniendo la posibilidad que sostengan su inocencia (el conocido como Alford Plea ${ }^{15}$ ); existencia de reglas obligatorias con mínimos de sentencia altas en delitos como las drogas y las armas de fuego que incentivan la confesión como única forma de evitar esos mínimos; y, reglas y prácticas de los sistemas de conmutación o condonación de penas basadas en la idea que los condenados asuman su culpabilidad para hacerse operativas (Bibas, 2014, p. 161) ${ }^{16}$. Finalmente, da cuenta cómo desde la investigación científica se ha acreditado que influyen también algunos factores psicológicos de los propios imputados en su decisión de declararse culpables a pesar de ser inocentes (por ejemplo la aversión al riesgo o de categorías de personas más vulnerables a las presiones tales como los jóvenes o las personas con retardos mentales) (Blume y Helm, 2014, pp. 161-162) ${ }^{17}$.

En Inglaterra y Gales también se han generado preocupaciones similares a la de los Estados Unidos. Si bien ellos no cuentan con un sistema procesal completamente equivalente al norteamericano, en la práctica la tasa promedio de guilty plea ha ido en aumento históricamente y se asemejan mucho en la actualidad. Así, las

\footnotetext{
${ }^{14}$ Se trata de una campaña organizada en conjunto por el Innocence Project (2018) y el Innocence Network de dicho país.

${ }^{15}$ El Alford Plea constituye una forma especial de Guilty plea admitida en el año 1970 por la Corte Suprema de los Estados Unidos en el caso North Carolina v. Alford, 400 U.S. 25 (1970) y que explícitamente permite que la persona se declare culpable pero manteniendo su inocencia (Dressler y Michaels, 2006, pp. 186-186). En el año 2004 se estimaba representaban un 8,5\% del total de los Guilty plea, (GiIliéron, 2013, p. 254).

${ }^{16}$ Consistentes con estos factores véase también: Blume y Helm (2014 pp.164-172).

${ }^{17}$ Sobre la investigación psicológica en la materia y su impacto en las confesiones y declaraciones de culpabilidad, véase, Leo (2009, pp. 195-236).
} 
estadísticas del año 2015 muestran que aproximadamente el 90\% de las condenas se obtuvieron por dicha vía y en su gran mayoría producto de una negociación previa (plea bargaining) (Horne, 2016, p. 21) ${ }^{18}$. En este contexto, un elemento importante de estudio y debate se ha dado acerca de la posibilidad que inocentes se declaren culpables. Si bien no se disponen datos actuales equivalentes a los de Estados Unidos, investigaciones empíricas llevadas adelante en la década de los '70 del siglo pasado en Inglaterra y Gales determinaron porcentajes fluctuantes entre $18 \%$ y $34 \%$ en los que existe una probabilidad fuerte que personas inocentes se hayan declarado culpables y hayan sido condenadas (Horne, 2016, pp. 50-51). Como se puede observar, se trata de un problema significativo.

La investigación más reciente disponible ha identificado que el riesgo de inocentes condenados previa declaración de culpabilidad se produce como producto de presiones sistémicas que se generan en el funcionamiento cotidiano de la justicia penal, tales como las ofertas de cambios en los cargos y de rebaja de penalidades que realizan los fiscales para obtener la declaración de culpabilidad; las presiones que los propios defensores hacen a sus clientes para declararse culpables; $y$, la aproximación de los jueces a estas materias en las que aparentemente privilegian su rol en la gestión del sistema por sobre otros valores (Horne, 2016) ${ }^{19}$. Como se puede observar, existe bastante consistencia con elementos identificados en la experiencia de los Estados Unidos.

La posibilidad que inocentes sean condenados en este tipo de procedimientos es un problema que también es mencionado en la literatura de países de tradición continental, aún con algo de menos intensidad que en el mundo anglosajón ${ }^{20}$. Alguna literatura sugiere que esto sería producto de las limitaciones normalmente establecidas en las legislaciones continentales al tipo de casos (exclusión de los más graves) en que se pueden negociar ${ }^{21} y$, además, debido a que este tipo de procedimientos se llevan adelante -producto de la lógica de diseño de los sistemas de Europa continental- en contextos mucho menos coercitivos que el que se da, por ejemplo, en los Estados Unidos (Guilliéron, 2013, pp. 250-251). Por otra parte, estas preocupaciones normalmente se manifiestan sin contar con datos empíricos como los revisados previamente. No obstante esto, la introducción de diversos tipos de procedimientos consensuales similares a nuestro abreviado, es decir, que permiten dictar sentencias sin necesidad de juicio oral y basándose fuertemente en la confesión de

\footnotetext{
${ }^{18}$ En la misma dirección pero con datos más antiguos véase: McConville y Marsh (2014, p. 217).

${ }^{19}$ En las páginas 51 y 57 se encuentra el desarrollo resumido. Los resultados de la investigación empírica entre pp. 177 a la 248, véase además, Horne (2013). Un análisis crítico al rol que juegan fiscales, jueces y defensores en Inglaterra y Gales en las declaraciones de culpabilidad de los imputados en: McConville y Marsh (2014, pp. 127-189). Sobre el tema de las presiones que ejerce la propia defensa en los mismos países puede verse: Naughton (2013, pp. 80-82). Sobre el problema de la negociación de cargos de parte del fiscal y las ofertas de pena más bajas a cambio de la declaración de culpabilidad y su impacto en personas inocentes en Gran Bretaña véase: Belloni y Hodgson (2000, pp. 141-144).

${ }^{20}$ Hay otros países pertenecientes al mundo anglosajón que no he revisado en el texto principal en los que se debate el problema en términos muy similares a los ya expuestos para los casos de Estados Unidos, Inglaterra y Gales. Por ejemplo, en Canadá, véase: Broackman (2010).

${ }^{21}$ En esta dirección, pero advirtiendo de una tendencia creciente a ampliar el margen de procedencia de este tipo de procedimientos en Europa. Killias (2010, pp. 143-144).
}

Rev. derecho (Coquimbo, En línea) 2019, 26: e3845 
parte de los imputados, han generado críticas y preocupaciones desde el punto de vista del impacto en la condena de inocentes en países como Alemania y Suiza (GuiIliéron, 2013, pp. 249-250). También se han levantado voces que ponen en duda la capacidad de dichos sistemas de justicia penal de asegurar una real voluntariedad de los imputados (Albrecht, 2001, p. 55) 22.

Críticas de esta naturaleza tampoco son desconocidas en la región, aun cuando el foco ha estado centralmente en otros aspectos de la institución que indirectamente tocan al problema de inocentes. Por ejemplo, se ha criticado el impacto que tendrían estos procedimientos en la ampliación del poder punitivo del sistema, en la falta de equilibro que existiría entre las partes que son llamadas a negociar ${ }^{23}$ y también la afectación que producirían a garantías centrales del Estado de Derecho (como el derecho a un juicio previo y la presunción de inocencia) (Díaz Cantón, 2001). Todas estas críticas podrían tener como un corolario natural el aumento de probabilidades de condenas de inocentes. Con todo, este punto no ha sido hasta el momento el central en el debate de este tipo de procedimientos en la región ${ }^{24}$.

\subsection{El problema especial de los delitos de menor gravedad}

Como se ha visto en la sección previa, buena parte de los temores acerca del impacto de los procedimientos consensuales en la condena de inocentes se ha basado en su potencial carácter coercitivo. Este surgiría principalmente de la amenaza de imposición de penas significativamente altas que podrían realizar los fiscales en caso de no aceptarse la negociación y ello llevaría a personas inocentes a preferir declararse culpables que correr el riesgo de ir a un juicio en que los resultados podrían ser de mucha gravedad (en el caso extremo incluso pena de muerte). Esto ha hecho que los riesgos que se generan en procedimientos especiales que trabajan con delitos cuyas penas son de mediana o menor entidad históricamente hayan sido menos visibilizados o se les haya asignado menos importancia en el debate sobre estas materias. Como en esos delitos la posibilidad de "amenazar" al imputado con penas altas no es posible o está al menos severamente limitada, ello se ha traducido en una menor preocupación por los riesgos que se producen en su desarrollo. Con todo, esto ha comenzado a cambiar en los últimos años. Así, es posible detectar una preocupación creciente en el ámbito comparado por el tratamiento de "delitos menores" y su potencial incidencia en la condena de inocentes.

En los Estados Unidos, por ejemplo, existe información que indica que tratándose de imputaciones por delitos de menor o relativamente menor gravedad existe aún más riesgo que imputados inocentes se declaren culpables. Blume y Helm (2014) hacen el ejercicio de identificar tipos de imputados que se declaran culpables en juicio, distinguiendo tres categorías principales ${ }^{25}$. Ellos afirman que la categoría más

\footnotetext{
${ }^{22}$ Apuntando en esta dirección, la organización Fair Trails (2018) documenta el caso de una acusada que se declara culpable a pesar de su inocencia en España.

${ }^{23}$ Por ejemplo, Anitúa (2001) "El juicio penal abreviado como una de las reformas penales de inspiración estadounidense que posibilitan la expansión punitiva".

${ }^{24}$ Una versión actualizada de las principales críticas en la región puede verse en: Anitúa (2017, pp. 97122).

${ }^{25}$ Los autores agregan en su análisis dos categorías secundarias pero que no son objeto de desarrollo en el texto principal de su trabajo sino sólo como nota a pie de página.
} 
cuantiosa corresponde precisamente a la de personas inocentes imputadas por delitos relativamente menores Blume y Helm (2014, p. 173). Un problema eso sí es que no existen cifras exactas acerca de la magnitud de este fenómeno. Si bien en todo tipo de casos es difícil identificar a las condenas erróneas, los problemas parecen amplificarse en materia de delitos menores producto del tratamiento mucho más informal que hacen los sistemas de justicia criminal respecto de ellos y el menor registro y seguimiento de los mismos, entre otras razones. Esto se explica ya que en estos delitos la posibilidad de controlar el error con posterioridad a su condena es muy baja en comparación con imputaciones de mayor gravedad, por ejemplo, interponiendo el equivalente funcional a nuestro recurso de revisión (Natapoff, 2012) ${ }^{26}$. Ello produciría que la cifra negra de condenas erróneas en estos casos debiera ser mucho más alta que en procedimientos normales ${ }^{27}$. Más allá de estas dificultades, lo que es claro es que se trataría de un problema que tiene enormes dimensiones debido a la cantidad de casos de pequeña magnitud que se tramitan en los Estados Uni$\operatorname{dos}^{28}$.

La literatura en los Estados Unidos también ha tratado de explicar qué es lo que llevaría a imputados inocentes declararse culpables en los delitos menores. Blume y Helm (2014, p. 174) sostienen que la razón central es que su declaración de culpabilidad sería el vehículo más sencillo y fácil para obtener su libertad inmediata. Se trataría de un poderoso incentivo que juega en conjunto con el hecho de que en su mayoría se trataría de imputados pobres, que no cuentan con asesoría legal o ésta es de baja calidad ${ }^{29}$ y que cuentan normalmente con algún tipo de antecedente penal previo, por lo que la declaración de culpabilidad no agregaría un nuevo estigma a su actual condición.

\footnotetext{
${ }^{26}$ Sostiene la misma idea: King (2013, p. 22). En esta misma dirección, la investigación empírica disponible en Chile da cuenta que los casos de recursos de revisión acogidos por la Corte Suprema serían en promedio más graves (penas superiores) que los que se condenan, ver: Duce Julio (2017, pp. 16-17).

${ }^{27}$ Gross (2008, p. 180) señala que en este tipo de delitos las condenas erróneas son casi indetectables a pesar que es probable que sean mucho más frecuentes que en delitos comunes. Citando un reporte elaborado por defensores en materia de delitos menores, Roberts $(2011$, p. 286) señala que no hay estudio que cuantifique el número de condena de inocentes en estos casos, pero ellos podrían ser cientos de miles.

${ }^{28}$ Por ejemplo, se estima que en el año 2008 el $80 \%$ del total de casos trabajados por los tribunales penales estatales eran misdemeanor o delitos menores (generalmente penados con multas o penas privativas de libertad de corto tiempo). Dato del National Center for State Courts citado en: Natapoff (2012, p. 103). Roberts (2011, pp. 280-282) indica que en un estudio de cortes estaduales en 11 estados en el mismo año 2008 arrojó como resultado que el 79\% de los casos correspondía a esta categoría. Además, muestra una clara tendencia al alza. Así entre 1972 y 2006 el total de ingresos por misdeamenors se habría duplicado en los Estados Unidos. Datos más recientes del año 2016 producidos por el National Center for States Courts muestran las mismas tendencias anteriores. Por ejemplo, en los tres estados con mayor cantidad de ingresos que aparecen en su base de datos, los porcentajes de misdemeanors por sobre el total de casos están alrededor o sobre el 80\%. Así ocurre en Texas (86\%), Carolina del Norte (82\%) y California (80\%). Las cifras de estos y otros Estados pueden revisarse en Schauffler, LaFountain, Strickland, Holt y Genthon (2017).

${ }^{29}$ Sobre el rol de los defensores en particular, Benner (2012, p. 9) destaca las presiones que surgen de las pesadas cargas de trabajo que manejan defensores públicos que les deja muy poco espacio para entrevistar a sus clientes y no les da tiempo ni recursos para realizar algún tipo de investigación previa a las negociaciones con el fiscal que le permitan controlar la calidad de sus casos. Eso se extrema tratándose de los delitos menores. Todo ello genera una presión sistemática para aceptar ofertas del fiscal y recomendar a sus clientes declararse culpables.
} 
Roberts (2011, pp. 306-309) destaca, por su parte, la existencia de presiones institucionales de todos los actores (fiscales, jueces y defensores) por disponer tempranamente (en la primera audiencia) de los casos menores como forma de manejar y alivianar sus cargas de trabajo y también da cuenta del rol que juega la privación de libertad de imputados pobres que no están en condiciones de pagar su fianza como un incentivo clave. Todo ello generaría un ambiente coercitivo que explicaría las declaraciones de culpabilidad de inocentes. Estos análisis también coinciden con los que realiza Natapoff. Ella destaca adicionalmente los problemas que surgen de arrestos con poca o derechamente nula evidencia que llevan al procesamiento de estos casos; las fallas de los fiscales en analizar y filtrar bien estos casos de arrestos improcedentes; la falta de abogados defensores para atender a los imputados en delitos menores; $y$, al igual que otros autores, la existencia de un conjunto de presiones para declararse culpable (de nuevo por el uso de privación de libertad, la falta de acceso a información de los antecedentes que existen en su contra y derivada del trabajo de todos los actores del sistema) (Natapoff, 2012).

Un factor común detrás de estas explicaciones, que excede el ámbito específico de los inocentes condenados, es que los sistemas de justicia penal tienden a trabajar en medio ambientes de alta carga laboral, donde desarrollan prácticas de trabajo extraordinariamente rutinarias con amplios espacios de discrecionalidad, bajos niveles de calidad, poca transparencia y control externo, y con a una enorme presión de disponer tempranamente la mayor cantidad de casos posibles. Ello se intensifica tratándose del tratamiento de delitos menores como ha sido descrito por la literatura (Feeley, 1992 y Bach, 2009).

El problema descrito no es patrimonio exclusivo de los Estados Unidos. En el ámbito europeo se trata también de un tema que genera creciente preocupación y debate. En esta dirección, Killias (2010, p. 144) ha sostenido que la tendencia a ampliar el ámbito de aplicación de diversos tipos de procedimientos simplificados en Europa podría ser la causa de muchas condenas erróneas. Ello obedecería a que en delitos de menor entidad son admitidas formas de negociación similares al plea bargaining de los Estados Unidos y ello explicaría, en su opinión, por qué la mayoría de las condenas a inocentes conocidas en Europa lo sean en este tipo de delitos y procedimientos (Killias, 2013, p. 66).

Refiriéndose al caso de Suiza, Gilliéron (2013, pp. 242-243 y 2013b) reporta que en los procedimientos por orden penal ha sido frecuente encontrar casos de condenas erróneas de personas fácticamente inocentes ${ }^{30}$. Killias (2010, pp. 150-151) analiza con más detalle estos datos dando cuenta que se trata de más de 200 inocentes condenados por delitos menores que fueron exonerados en un período de 10 años (1995-2004). En su análisis encuentra como patrón común la falta de defensa adecuada y el carácter excesivamente sumario de estos procedimientos. Además, enfatiza que tres de cada cuatro condenas penales en Suiza se obtienen por este procedimiento, lo que hace muy probable que la condena de inocentes sea mucho más frecuente en delitos menores que en otra clase de infracciones (Killias, 2010, p. 151).

\footnotetext{
${ }^{30}$ Se trata de un tipo de procedimiento sumario o simplificado parecido a nuestro procedimiento monitorio pero que incluye a simples delitos y no sólo faltas.
} 
Junto con la experiencia comparada, existe también evidencia científica que muestra que, en el contexto de infracciones menores, es frecuente que personas inocentes estén dispuestas a confesar un delito que no han cometido a cambio de la obtención de un beneficio. Es decir, que las personas prefieren asegurar una sanción menor aun cuando no hayan cometido una infracción que a enfrentar el riesgo de ser sancionadas a penas mayores ${ }^{31}$. Uno de los trabajos más novedosos y recientes estuvo constituido por un experimento que intentó determinar la entidad del riesgo de confesiones falsas en contextos de negociación muy similares a los que se producen en delitos menores (Dervan y Edkins, 2013, pp. 33-37) ${ }^{32}$. Los resultados del experimento muestran que un $89,2 \%$ de los "culpables" estuvieron dispuestos a declararse como tales, pero que también un $56 \%$ de los inocentes estuvieron dispuestos a confesar su culpabilidad con el objetivo de evitar el problema que significa llevar adelante un proceso para determinar su inocencia, y obtener así de manera rápida una sanción más benigna que les fue ofrecida como alternativa.

La información comparada, sumada a la evidencia científica disponible, muestra que el riesgo de condena de inocentes en procesos consensuales no es sólo un problema que se produce en los delitos que tienen asociadas penas más graves, sino también a los de menor intensidad. También sugiere que es posible que en estos últimos la cantidad de errores sea superior debido al peso estadístico que tienen estas infracciones en el funcionamiento cotidiano de los sistemas de justicia criminal contemporáneos y la tendencia de operar con menor rigor y control en su desarrollo. Con esto en mente paso a revisar la realidad nacional.

\footnotetext{
${ }^{31}$ Los aportes de la ciencia en la materia son bastante interesantes y cubren diversos estudios. Uno de los primeros en el área tuvo por objeto identificar la influencia de modelos de interrogación basados en la psicología en la generación de confesiones falsas y verdaderas. Entre los hallazgos se pudo determinar que las personas que efectivamente cometieron una infracción son más proclives a declararse culpables, pero que también los interrogatorios basados en la minimización de la infracción y el ofrecimiento de tratos favorables al imputado aumentan la probabilidad de confesiones tanto verdaderas como falsas (Russano, Meissner, Narchet. y Kassin, 2005).

${ }^{32}$ En el experimento se acusa a estudiantes universitarios, que se han ofrecido voluntariamente para participar en un estudio sobre trabajo individual y en equipo, de haber copiado. Para participar en dicha investigación se les ofrece una remuneración por el tiempo invertido. El día del experimento el voluntario es reunido con otro "estudiante" que es una persona que realmente pertenece al equipo de investigadores y se les pide resolver tres problemas individualmente y tres en equipo, con expresa instrucción de no comunicarse entre ellos durante el trabajo individual ya que se les dejara solos en la respectiva sala. En la mitad de los casos la persona que forma parte del equipo de investigación tiene la instrucción de comunicarse con el estudiante voluntario mientras realizan los ejercicios individuales y en la otra mitad seguir las instrucciones y no sostener contacto alguno. Una vez concluido el trabajo, un ayudante responsable de supervisar su desarrollo los acusa de haber infringido la regla y haber copiado, afirmando que como indicio tiene la similitud de resultados que se produjo entre ambos que sólo en un $4 \%$ de los casos se podría explicar cómo una casualidad. Les advierte que esta imputación podría generar algunas consecuencias académicas de cierta magnitud. Con todo, en caso de reconocer en ese momento se le ofrece un tratamiento atenuado o más benigno de consecuencias. Se trata de un escenario que perfectamente podría considerarse como equivalente al tipo de respuestas que los sistemas de justicia penal ofrecen a delitos menores.
} 


\section{El procedimiento abreviado y el simplificado con reconocimiento de responsabilidad: resultados y hallazgos de la investigación}

Como señalaba en la introducción, el sistema acusatorio introdujo a nuestro ordenamiento procesal penal el procedimiento abreviado y el simplificado ${ }^{33}$. En este último se reguló una modalidad que permite que el imputado reconozca responsabilidad (Ley 19.696, 2000, art. 395) y se dé lugar a una forma de procedimiento muy similar a la del abreviado. Como describe Riego Ramírez (2017), ambos procedimientos se caracterizan por "...la renuncia al juicio oral por parte del imputado y su reemplazo por una forma de juzgamiento simplificada, basada en el reconocimiento de los hechos por parte del imputado y la lectura de la carpeta de la investigación del fiscal, ....y la aceptación de responsabilidad en procedimiento simplificado..."(p. 1086). En buenas cuentas, con matices y modalidades diversas, ambos introducen procedimientos basados en la lógica de la negociación y el consenso en nuestro sistema (Ried Undurraga, 2017, p. 580) ${ }^{34}$. Por lo mismo, han sido objeto de importantes polémicas desde prácticamente la discusión parlamentaria, especialmente tratándose del procedimiento abreviado.

Si se revisa la doctrina nacional, la mayor parte de las críticas no han estado dirigidas al tema central de este trabajo, sino a otros problemas teóricos y prácticas de su uso ${ }^{35}$. Uno de los pocos textos que se ha pronunciado sobre el problema en estudio, además desde los años iniciales de funcionamiento del sistema acusatorio, ha sido el de Horvitz Lennon y López Masle (2005), partiendo de la crítica que se ha formulado en el ámbito comparado al procedimiento abreviado, ella identifica el riesgo que "Incluso el imputado inocente podría preferir el pacto frente a la disyuntiva entre libertad o prisión preventiva o condena a una pena reducida y el albur de un juicio que puede terminar con la absolución, pero también con una pena mucho más grave" ( $\mathrm{p}$. $512)^{\prime \prime 36}$. En la parte final de su análisis luego agrega que el procedimiento simplificado con reconocimiento de responsabilidad genera riesgos similares (Horvitz Lennon y López Masle, 2005, p. 516). Doctrina más reciente ha comenzado a plantear el problema específico del uso del procedimiento abreviado y simplificado con admisión

\footnotetext{
33 Una revisión de los principales debates doctrinarios que hubo en torno a la regulación de ambos procedimientos en el proyecto del Código Procesal Penal y luego en el debate legislativo puede verse en, Riego Ramírez (2000).

${ }^{34}$ Describe con más detalle esta idea de la siguiente forma "Los procedimientos abreviado y simplificado autorizan al Ministerio Publico a negociar con el imputado y su defensa; el persecutor obtiene generalmente colaboración para la investigación -información importante, hechos reveladores respecto de otros imputados, una reparación a la víctima- y el imputado, a su vez, obtiene una rebaja en la pena que se solicitara aplicar. Muchas veces lo que se negocia por el imputado es una pena no privativa de libertad. Este intercambio, sin embargo, tiene un precio para ambos intervinientes. El Ministerio Publico renuncia a la pena máxima que puede solicitar respecto del imputado que negocia; el imputado renuncia, a su vez, a su presunción de inocencia reconociendo los hechos o la responsabilidad materia de la investigación. Por su parte, el Tribunal de Garantía evita seguir adelante con el proceso, limitándose a dictar sentencia sobre la base de lo investigado por el Ministerio Publico, de la pena pedida por este, y del reconocimiento efectuado por el imputado. Se ahorran así recursos para el Estado, y el imputado evita tener que afrontar las consecuencias negativas que el proceso penal necesariamente ocasiona, siendo quizás la más importante la incertidumbre acerca de su resultado".

${ }^{35}$ Ried Undurraga (2017) hace un resumen de la crítica que ha formulado la doctrina nacional a estos procedimientos consensuales.

${ }^{36}$ En esta materia cita sobre el punto a autores como Alschuler, Ferrajoli y Langbein.
} 
de responsabilidad como factores que podrían incidir en la condena de personas inocentes (Duce Julio, 2013, pp. 110-111) (17 $^{37}$ de hecho ha identificado y analizado casos en que esto ha ocurrido (Duce Julio, 2015, pp. 181-188). ${ }^{38}$ Finalmente, la reforma introducida por la Ley 20.931 (2016) (la conocida como agenda corta antidelincuencia), ha reforzado la crítica acerca del potencial carácter coercitivo que podrían adquirir este tipo de procedimientos $y$, por lo mismo, de manera indirecta se ha manifestado su preocupación por el impacto que podría generar en aumentar los incentivos para su uso de parte de personas inocentes (Riego Ramírez, 2017) ${ }^{39}$. El cuestionamiento central desde esta perspectiva sería que la nueva legislación ha amplificado los problemas potenciales de falta de voluntariedad real de los imputados al momento de aceptar estos procedimientos ${ }^{40}$.

Más allá de este limitado grupo de autores, el tema no se ha planteado con mucha fuerza a pesar que con el transcurso del tiempo estos dos procedimientos han ido adquiriendo mayor relevancia en el funcionamiento concreto del sistema.

\subsection{La importancia estadística de los procedimientos abreviados y simpli- ficados}

En la presente sección se entregan datos estadísticos con el propósito de mostrar la incidencia real que tienen estos procedimientos en el funcionamiento cotidiano de nuestra justicia penal. Una advertencia básica al lector es que las cifras entre las distintas instituciones no coinciden en sus números específicos, pero más allá de ello parecen mostrar una tendencia idéntica ${ }^{41}$.

Las cifras del Ministerio Público, resumen el número total de sentencias definitivas y su porcentaje dictadas los años 2015 y 2016, distinguiendo si emanaron de un juicio oral ordinario, de un procedimiento abreviado y de uno simplificado (Tabla 1). Se ha excluido de esta presentación las sentencias obtenidas en procedimientos monitorios ya que estimo ellas distorsionan el análisis por dos razones. Al tratarse de faltas que sólo son susceptibles de ser sancionadas con una multa nuestra legislación

\footnotetext{
${ }^{37}$ El texto plantea que no debiera descartarse la posibilidad de inocentes condenados tanto en los procedimientos abreviados como simplificados con reconocimiento de responsabilidad en atención al alto porcentaje de condenas que generan.

${ }^{38}$ En este trabajo se analizan en detalle dos casos concretos de condenas de inocentes en procedimientos simplificados con reconocimiento de responsabilidad en los que la Corte Suprema acogió recursos de revisión.

${ }^{39}$ Una visión general de esta reforma legal puede verse en Cerda San Martín (2016).

${ }^{40}$ Se trata de un problema clave en estos procedimientos. Con todo, el foco de mi presentación estará en las condenas erróneas. Como existe una relación entre ambos fenómenos me referiré en algunos pasajes a los problemas de falta de voluntariedad cuando ellos surjan asociados al del objeto central del estudio.

${ }^{41}$ La falta de coincidencia entre las cifras del Ministerio Público con la de la Defensoría Penal Pública puede ser explicada debido a que ambas instituciones trabajan con universos diferentes de casos. Con todo, he encontrado también diferencias importantes entre las cifras de una misma institución que son publicadas o he adquirido por vías diversas y, en todo caso, también tienen diferencias importantes con las que he podido conseguir del Poder Judicial. Estadísticas complementarias a las que citaré hasta el año 2014-2015 pueden revisarse en el reciente trabajo publicado por el Centro de Estudios de la Justicia de las Américas (CEJA) especialmente en el anexo (Fandiño Castro, Rua, Moreno Holman y Fibla Cerda, 2017). Un análisis detallado de estas cifras mostrará discrepancias importantes entre ellas también.
} 
no regula una audiencia en la que se realice la determinación judicial de la pena. Además, a falta de reclamo dentro de plazo y habiendo incentivos para el pago de la multa, es muy difícil comprobar la existencia de condenas erróneas en este tipo de procedimientos ${ }^{42}$.

Tabla 1: Total de sentencias y \% por tipo de procedimientos años 2015-2016

\begin{tabular}{|l|lc|lc|}
\multicolumn{1}{c|}{} & \multicolumn{2}{c}{2015} & \multicolumn{2}{c|}{2016} \\
\multicolumn{1}{c|}{} & $\mathrm{N}^{\circ}$ & $\%$ & $\mathrm{~N}^{\circ}$ & $\%$ \\
\hline Juicio oral & 27.760 & $(16,23 \%)$ & 27.121 & $(16,83 \%)$ \\
\hline Abreviado & 32.368 & $(18,92 \%)$ & 32.283 & $(20,04 \%)$ \\
\hline Simplificado & 110.891 & $(64,84 \%)$ & 101.670 & $(63,12 \%)$ \\
\hline Total & $\mathbf{1 7 1 . 0 1 9}$ & $\mathbf{( 1 0 0 \% )}$ & $\mathbf{1 6 1 . 0 7 4}$ & $\mathbf{( 1 0 0 \% )}$ \\
\hline
\end{tabular}

Fuente: elaboración propia sobre la base de Estadísticas del Ministerio Público ${ }^{43}$.

De acuerdo a lo que muestra la Tabla 1, tanto el procedimiento simplificado como el abreviado, considerados individualmente superan el total de sentencias dictadas en juicios orales del procedimiento ordinario. Especialmente relevante es el procedimiento simplificado que supera a los otros dos, incluso si se suman. Por otra parte, si se agrupan las sentencias de abreviado y simplificado, ambas categorías representan más de 83\% del total de sentencias tanto el 2015 como el 2016, es decir, por lejos la gran mayoría de las que produce el sistema.

La Tabla 2 desagrega las sentencias tanto en número y porcentajes de acuerdo a su naturaleza: condenatoria o absolutoria. Para simplificar la Tabla 2, ésta sólo contiene los datos de 2016 que, en todo caso, son bastante similares a los del año previo.

Tabla 2: Total de sentencias y \% por naturaleza y tipo de procedimientos año 2016

\begin{tabular}{|l|lllll|ll|}
\hline \multicolumn{1}{c}{\begin{tabular}{c}
\multicolumn{1}{c}{ Año } \\
\multicolumn{1}{c}{2016}
\end{tabular}} & \multicolumn{2}{c}{ Condenatorias } & \multicolumn{2}{c|}{ Absolutorias } & \multicolumn{2}{c|}{ Total } \\
$\mathbf{N}^{\circ}$ & \multicolumn{1}{c}{$\%$} & \multicolumn{1}{c}{$\mathbf{N}^{\circ}$} & \multicolumn{1}{c}{$\%$} & $\%$ \\
\hline Juicio oral & 18.537 & $(68,35 \%)$ & 8.584 & $(31,65 \%)$ & 27.121 & $(100 \%)$ \\
\hline Abreviado & 32.136 & $(99,54 \%)$ & 147 & $(0,46 \%)$ & 32.283 & $(100 \%)$ \\
\hline Simplificado & 91.319 & $(89,88 \%)$ & 10.351 & $(10,18 \%)$ & 101.670 & $(100 \%)$ \\
\hline Total & $\mathbf{1 4 1 . 9 9 2}$ & $\mathbf{( 8 8 , 1 5 \% )}$ & $\mathbf{1 9 . 0 8 2}$ & $\mathbf{( 1 1 , 8 4 \% )}$ & $\mathbf{1 6 1 . 0 7 4}$ & $\mathbf{( 1 0 0 \% )}$ \\
\hline
\end{tabular}

\footnotetext{
${ }^{42}$ Recordemos que de acuerdo a la Ley 19.696 (2000, art. 392) el requerimiento fundado presentado por el fiscal al juez de garantía permite a éste acogerlo, resolución que normalmente se transforma en sentencia ejecutoriada cuando el imputado paga dentro de los 15 días siguientes o no reclama en dicho plazo. El autor agradece la sugerencia planteada por uno de los evaluadores anónimos en esta explicación.

${ }^{43}$ Datos enviados por Ministerio Público por vía electrónica el 1 de febrero de 2017 en virtud a requerimiento por transparencia presentado por Zagmut Venegas (N. R.: archivo en poder del autor).
} 
Los datos permiten apreciar que un porcentaje muy mayoritario del total de las sentencias en el año son condenatorias (88,15\%). Sólo en el caso del juicio oral el porcentaje de absoluciones es significativamente superior al promedio (31,6\%). Ahora bien, si se considera exclusivamente el universo de sentencias condenatorias (141.992), es posible afirmar que un $86,9 \%$ provienen de procedimientos abreviados $(22,6 \%)$ y simplificados (64,3\%). Esta cifra nos muestra que ambos procedimientos son los principales productores de condenas en Chile.

Las Tablas 3 y 4 hacen el mismo ejercicio que las anteriores pero sobre la base de las estadísticas proporcionadas por la Defensoría Penal Pública.

Tabla 3: Total de sentencias y \% por tipo de procedimientos años 2015-2016

\begin{tabular}{|l|cc|cc|}
\multicolumn{1}{c|}{} & \multicolumn{2}{c}{2015} & \multicolumn{2}{c|}{2016} \\
\multicolumn{1}{c|}{} & $\mathrm{N}^{\circ}$ & \multicolumn{1}{c|}{$\%$} & $\mathrm{~N}^{\circ}$ & $\%$ \\
\hline Juicio oral & 16.056 & $(12,07 \%)$ & 16.583 & $(13,05 \%)$ \\
\hline Abreviado & 21.848 & $(16,43 \%)$ & 22.374 & $(17,61 \%)$ \\
\hline Simplificado & 95.048 & $(71,48 \%)$ & 88.058 & $(69,32 \%)$ \\
\hline Total & $\mathbf{1 3 2 . 9 5 9}$ & $\mathbf{( 1 0 0 \% )}$ & $\mathbf{1 2 7 . 0 1 5}$ & $(\mathbf{1 0 0 \% )}$ \\
\hline
\end{tabular}

Fuente: elaboración propia sobre la base de Estadísticas de la Defensoría Penal Pública ${ }^{45}$

Al igual que en el caso de las cifras del Ministerio Público, la Tabla 3 muestra que la mayor cantidad de sentencias se obtienen en procedimientos abreviados y simplificados. Incluso el promedio de ambas categorías sumadas para los dos años supera el $86 \%$ que es un poco superior a las del Ministerio Público, pero se encuentran en un rango muy similar. La Tabla 4 especifica nuevamente la naturaleza de sentencia por tipo de procedimiento con foco en el año 2016.

Tabla 4: Total de sentencias y \% por naturaleza y tipo de procedimientos año 2016

\begin{tabular}{|l|lll|ll|ll|}
\hline \multicolumn{1}{c}{ Año } & \multicolumn{2}{c}{ Condenatorias } & \multicolumn{2}{c}{ Absolutorias } & \multicolumn{2}{c|}{ Total } \\
2016 & \multicolumn{1}{c}{$\mathrm{N}^{\circ}$} & \multicolumn{1}{c}{$\%$} & \multicolumn{1}{c|}{$\mathrm{N}^{\circ}$} & \multicolumn{1}{c}{$\%$} & $\%$ \\
\hline Juicio oral & 10.740 & $(64,76 \%)$ & 5.843 & $(35,23 \%)$ & 16.583 & $(100 \%)$ \\
\hline Abreviado & 22.277 & $(99,56 \%)$ & 97 & $(0,43 \%)$ & 22.374 & $(100 \%)$ \\
\hline Simplificado & 78.069 & $(88,65 \%)$ & 9.989 & $(11,34 \%)$ & 88.058 & $(100 \%)$ \\
\hline Total & $\mathbf{1 1 1 . 0 8 6}$ & $\mathbf{( 8 7 , 4 5 \% )}$ & $\mathbf{1 5 . 9 2 9}$ & $\mathbf{( 1 2 , 5 4 \% )}$ & $\mathbf{1 2 7 . 0 1 5}$ & $\mathbf{( 1 0 0 \% )}$ \\
\hline
\end{tabular}

Fuente: elaboración propia sobre la base de la Defensoría Penal Pública ${ }^{46}$

\footnotetext{
${ }^{44}$ Datos enviados por Ministerio Público por vía electrónica el 1 de febrero de 2017 en virtud a requerimiento por transparencia presentado por Zagmut Venegas (N. R.: archivo electrónico en poder del autor).

${ }^{45}$ Datos enviados la Defensoría Penal Pública por vía electrónica el 25 de enero de 2017, en virtud a requerimiento por transparencia presentado por Zagmut Venegas (N. R.: archivo electrónico en poder del autor).
} 
Los procedimientos abreviados y simplificados y el riesgo de condenas erróneas en Chile.

La tendencia identificada con las cifras del Ministerio Público se mantiene e intensifica en estos datos. La gran mayoría de las sentencias del año son condenatorias $(87,4 \%)$ y sumadas las de los procedimientos abreviados y simplificados representan el $91,3 \%$ de las condenas del período.

Como ha quedado claro en esta breve revisión, el procedimiento simplificado es el que mayor cantidad de sentencias y condenas produce. Con todo, las cifras del Ministerio Público y la Defensoría Penal Pública no discriminan si esos simplificados fueron con reconocimiento de responsabilidad o no. La alta tasa de condena (en promedio $89 \%$ ) permite presumir que en su gran mayoría se debiera tratar de procedimientos con reconocimiento de responsabilidad. Afortunadamente, pude conseguir algunas cifras del Poder Judicial que permiten precisar esto. El problema de ellas eso si es que en sus números absolutos están muy lejanas a las cifras anteriores, por lo que tomo sólo sus proporciones porcentuales para hacer una estimación del peso que tendrían los simplificados con reconocimiento de responsabilidad dentro del universo total en ese tipo de procedimiento especial. Teniendo presente esto, la tabla 5 presenta las estadísticas del Poder Judicial en materia del porcentaje de casos de los simplificados que son resueltos en la modalidad de reconocimiento de responsabilidad de la Ley 19.696 (2000, art. 395).

Tabla 5: \% casos del total de simplificados resueltos por art. 395 del Código Procesal Penal.

\begin{tabular}{|l|c|}
\hline \multicolumn{1}{|c|}{ Año } & $\%$ \\
\hline $2005-2016$ & $98,66 \%$ \\
\hline 2015 & $98,86 \%$ \\
\hline 2016 & $99,03 \%$ \\
\hline
\end{tabular}

Fuente: elaboración propia sobre la base de datos del Poder Judicial ${ }^{47}$

Se puede observar que para el período entre los años 2005 y 2016 el promedio de simplificados con reconocimiento de responsabilidad es altísimo (92,92\%) y que se trata de una cifra bastante constante si es que luego se ve el promedio anual en los años 2015 y 2016.

Junto con lo anterior, a partir de las estadísticas del Poder Judicial también es posible calcular la tasa de condena en esta modalidad del simplificado (porcentaje de condenas dentro del universo de casos que fueron resueltos con reconocimiento de responsabilidad). La tabla 6 muestra los resultados agrupados en el promedio entre los años 2005 a 2016 y luego de manera desagrega en los años 2015 y 2016.

\footnotetext{
${ }^{46}$ Datos enviados por la Defensoría Penal Pública por vía electrónica el 25 de enero de 2017, en virtud a requerimiento por transparencia presentado por Zagmut Venegas (N. R.: archivo electrónico en poder del autor).

${ }^{47}$ Datos enviados por Poder Judicial por vía electrónica el 1 de diciembre de 2017 (Oficio 17 DDI n 6510) en virtud a requerimiento por transparencia presentado por Ricardo Lillo (N. R.: archivo electrónico en poder del autor).
} 
Tabla 6: \% de condenas en simplificados resueltos por art. 395 del Código Procesal

Penal

\begin{tabular}{|l|c|}
\hline \multicolumn{1}{|c|}{ Año } & $\%$ \\
\hline $2005-2016$ & $92,92 \%$ \\
\hline 2015 & $93,29 \%$ \\
\hline 2016 & $90,59 \%$ \\
\hline
\end{tabular}

Fuente: elaboración propia sobre la base de datos del Poder Judicial ${ }^{48}$

El promedio de las sentencias condenatorias obtenidas en simplificados resueltos con reconocimiento de responsabilidad se acerca al 99\% y se trata también de una cifra bastante estable si se analiza anualmente los años 2015 y 2016, aun cuando con una tendencia a una pequeña alza sobre el promedio. Debe notarse que se trata de una tasa de condena muy similar a la que se obtiene en los procedimientos abreviados (un 99,5\% en los datos del Ministerio Público y la Defensoría Penal Pública), lo que es lógico ya que más allá de la terminología del Código Procesal Penal y casos en que se aplican, se trata de procedimientos que operan sobre la base de lógicas bastante similares.

En consecuencia, los datos disponibles muestran que los procedimientos simplificados con reconocimiento de responsabilidad son la principal vía para dictar sentencias condenatorias en nuestro país. Le sigue a distancia el procedimiento abreviado, pero en todo caso aportando cifras superiores a las de las condenas que se generan como consecuencia del juicio oral en el procedimiento ordinario. Por otra parte, cuando un caso va a cualquiera de estos dos procedimientos especiales, la probabilidad que se produzca una condena es altísima (entre un $98,7 \%$ y 99,5\%). Por lo mismo, mirar con mayor atención el cómo estos procedimientos son llevados adelante parece clave si es que se quiere identificar riesgos de potenciales condenas erróneas en nuestro sistema procesal penal y otros derivados de críticas más tradicionales, como por ejemplo, las vinculadas a la falta de voluntariedad en la aceptación de los mismos.

\subsection{Los procedimientos abreviados y simplificados con reconocimiento de responsabilidad y los riesgos de condenas erróneas en Chile}

El objetivo de esta sección será analizar los hallazgos principales de la investigación. Para estos efectos, partiré por mostrar brevemente la información que entrega la base de datos de los recursos de revisión resueltos por la Corte Suprema entre los años 2007 y 2016. Luego, con mayor extensión, me detendré en los aportes obtenidos por las entrevistas y el estudio empírico de observación de audiencias.

\footnotetext{
${ }^{48}$ Datos enviados por Poder Judicial por vía electrónica el 1 de diciembre de 2017 (Oficio 17 DDI n 6510) en virtud a requerimiento por transparencia presentado por Ricardo Lillo (N. R.: archivo electrónico en poder del autor).
} 
Los procedimientos abreviados y simplificados y el riesgo de condenas erróneas en Chile.

\subsubsection{La información disponible en la base de datos de los recursos de revi- sión 49}

La Corte Suprema ha acogido un total de 48 recursos de revisión de condenas generadas en el contexto de funcionamiento del sistema acusatorio entre los años 2007 y 2016. Dicha cifra representa aproximadamente un $8 \%$ del total de recursos presentados en el período (Duce Julio, 2017, p. 129). Si uno se detiene en el análisis de dichos casos, en su gran mayoría se trata de condenas obtenidas en procedimientos abreviados ( 7 casos, un 14,5\% del total) y simplificados (31 casos, un $64,5 \%$ del total). En su conjunto constituyen cerca del $80 \%$ del total de revisiones acogidas en el período ${ }^{50}$. El juicio oral ordinario sólo explicaría un $16,6 \%$ de las condenas erróneas ( 8 casos) en el mismo período. En términos generales, es posible apreciar una tendencia muy similar a la revisada en la sección previa, aun cuando con una pequeña diferencia a favor de los casos concluidos en juicio oral en desmedro de los de abreviado.

En 35 de estos 38 casos de condenas erróneas obtenidas en abreviados y simplificados ello correspondió a casos de suplantación de identidad ${ }^{51}$. De hecho, los siete abreviados corresponden a esta tipología y 28 de 31 de los simplificados (todos con admisión de responsabilidad). Si bien se trata de un tipo de condena errónea muy llamativa debido al factor que explica el error, lo cierto es que da cuenta de una vulnerabilidad importante de los abreviados y simplificados con reconocimiento de responsabilidad a la posibilidad de condenar equivocadamente a personas. En todos estos casos parece que la vertiginosidad del procedimiento, el escaso control realizado por los actores del sistema y la presión por sacar el caso adelante en forma rápida los lleva a cometer un error bastante básico como lo es el no verificar con cuidado la identidad de la persona a la que se condena ${ }^{52}$. Esto sugiere que en la tramitación de

\footnotetext{
49 Una revisión detallada de esta base de datos puede encontrarse en: Duce Julio (2017), otra versión previa y con algunas diferencias de contenidos en Duce Julio (2015b).

${ }^{50}$ Uno de los casos no contabilizado que permite superar ese porcentaje fue tramitado de acuerdo a las reglas del procedimiento por delito de acción penal privada (Ley 19.696, 2000, arts. 400-405) que cuenta como regla supletoria una remisión a las normas que regulan al simplificado (Ley 19.696, 2000, art. 405).

${ }^{51}$ Se trata de situaciones en que personas que son atrapadas por el sistema (típicamente en flagrancia), dan un nombre que han tomado de otra persona que no ha participado en el delito y el sistema no es capaz de darse cuenta de esto y condena a la persona equivocada. Ello se logra normalmente falsificando o dando uso incorrecto del número de carné de identidad del inocente suplantado. Esto lleva a que formalmente sea condenada la persona que fue atrapada por el sistema, pero oficialmente es la persona cuya identidad ha sido suplantada por el verdadero autor. Por lo general, se trata de casos en delitos contra la propiedad, con penas privativas de libertad bajas sustituidas por una pena alternativa y que se acuerdan en una etapa muy temprana del proceso con poco tiempo para haber verificado la identidad del supuesto autor. Además, en varios de los casos los suplantadores de identidad tienen alguna relación con el suplantado (por ejemplo son familiares, dentro de los que se incluyen hermanas y hermanos).

52 Para entender el problema de vertiginosidad actual del procedimiento abreviado es necesario recordar que la Ley 20.074 (2005) que flexibilizó la oportunidad y las formalidades para llevar adelante al abreviado, permitiendo que éste fuera solicitado desde la audiencia de formalización de la investigación y presentando acusación verbal. Algo similar ya se había hecho con la Ley 19.789 (2002, art. 393 bis) en materia de procedimiento simplificado. La falta de verificación mínima de un dato básico como la correcta identidad del imputado ha dado lugar recientemente a varios casos en los que la Corte Suprema, a propósito de conocer recursos de casación, ha confirmado condenas en contra del Estado para indemnizar perjuicios a favor de las víctimas de estos errores invocándose como título jurídico
} 
estos procedimientos se darían algunas de las presiones de carácter sistémico y procesos de burocratización del trabajo descritos en la literatura comparada que explican que las condenas erróneas en delitos de mediana y baja gravedad pueden ser aún más frecuentes que las que darían tratándose de casos más graves.

Junto con lo anterior, existen tres casos adicionales de procedimientos simplificados con reconocimiento de responsabilidad en la que se acogió el recurso de revisión ${ }^{53}$. Dicho de otra forma, una persona que perfectamente pudo haber sido absuelta por el delito imputado prefirió recibir una condena antes que arriesgarse a un juicio simplificado. El primero de estos casos es el de Diego Nieto quien fue condenado el año 2010 a 60 días de prisión en su grado máximo y a una multa (pena que fue objeto de remisión condicional), como autor del delito de conducción en estado ebriedad (Ley 18.290, 2009, art. 115, a). El recurso de revisión fue acogido al acreditarse que el condenado había sido sobreseído definitivamente por el mismo tribunal como consecuencia del cumplimiento de una suspensión condicional del procedimiento decretada varios meses antes de realizar el procedimiento simplificado en su contra (Contra Diego Nieto Vasquez, 2011). Luego está el caso de Jorge Antio, quien fue condenado el año 2012 como autor del delito flagrante de desacato de la Ley 19.696 (2000, art. 240), por el incumplimiento de la medida cautelar decretada en conformidad de la Ley 20.066 (2005, art. 10) (Ley sobre Violencia intrafamiliar). La condena fue a la pena de 61 días de presidio menor en su grado mínimo y a la accesoria legal de suspensión de cargo u oficio público durante la condena (pena sustituida por la de reclusión parcial nocturna). El recurso de revisión fue acogido unánimemente al acreditarse que la medida cautelar no estaba vigente al momento de su supuesto incumplimiento. Finalmente, está el caso de Víctor Moreno quien fue condenado el año 2013 como autor del delito de uso de licencia de conducir falsa previsto la Ley 18.290 (2009, art. 192, b) a la pena de 61 días de presidio menor en su grado mínimo, más accesorias legales, multa de un tercio de UTM e inhabilitación para obtener su licencia de conducir por el plazo de un año (pena de cumplimiento efectivo). El recurso de revisión fue acogido unánimemente al establecerse que la licencia de conducir que portaba era auténtica (Contra Victor Raul Moreno Delgado, 2013).

Estos casos sugieren, tal como lo hace la experiencia comparada, que la modalidad de reconocimiento de responsabilidad en el procedimiento simplificado genera un entorno de trabajo en el cual se producen naturalmente riesgos de condenas erróneas ${ }^{54}$. Revisemos esto con un poco más de detalle. En dos de estos casos (Antio y Moreno) nos encontramos con personas que son detenidas el día anterior a la audiencia y que, en esa calidad (privados de libertad), son conducidas a la misma. Se trata de audiencias que se llevan a efecto de manera bastante rápida y breve, con

fundante la Ley 19.640 (1999, art. 5) establece la responsabilidad del Estado por las "conductas injustificadamente erróneas o arbitrarias del Ministerio Público". (Palma Bustos, Felicinda con Fisco de Chile, 2017) y (Bustamante Cruz María Angélica con Fisco de Chile, 2017)

${ }^{53}$ Una presentación y análisis detallado de dos de estos tres casos en Duce Julio (2015, pp.164-169 y 181-201).

${ }^{54}$ Llama la atención que no se trata de casos con consecuencias menores para los condenados como en abstracto podría pensarse. Junto con la anotación prontuarial que la condena trae aparejada, en dos de los tres casos la sentencia significó privación de libertad efectiva (una en todo caso de pena sustitutiva de reclusión parcial nocturna). No estamos en consecuencia en presencia de un simple trámite. 
poca información, en un lenguaje que hace que sólo los iniciados puedan entender con claridad qué es lo que pasa en el desarrollo de las mismas, en donde los imputados han tenido poco o nulo contacto previo con sus defensores y en las que se presentan requerimientos de parte del Ministerio Público con una solicitud de pena que representa una baja muy sustancial respecto a la potencial pena que en abstracto se podría exigir de acuerdo a los tipos penales imputados ${ }^{55}$. En un escenario como el descrito es posible presumir que el nivel de conocimiento y comprensión real de lo que estaba en juego con la decisión de aceptar responsabilidad de parte de los imputados haya sido muy baja y eso hubiere sido un factor clave para el uso de la Ley 19.696 (2000, art. 395). Por otra parte, el entorno descrito es propicio para generar un escenario de coerción de los imputados que los lleve a reconocer algo que no han hecho como forma de concluir rápidamente el proceso en su contra (eventualmente obteniendo su libertad) y evitar consecuencias mayores. En esta dirección, por ejemplo, el recurso de revisión presentado en favor de Víctor Moreno señala que el reconocimiento de responsabilidad fue dado por "temor a permanecer detenido, desconocimiento de la normativa por su calidad de extranjero."(Contra Victor Raul Moreno Delgado, 2013). Además, el beneficio que se obtiene al declarar la responsabilidad (asociado a la obtención de libertad) es muy grande y establece un fuerte incentivo para el reconocimiento.

Estos casos también dan cuenta de la falta de rigor en los procesos de trabajos en delitos de mediana y baja gravedad. El caso de Jorge Antio es un ejemplo paradigmático de esto. El señor Antio fue requerido por el Ministerio Público como autor del delito de desacato fundado en el incumplimiento de una medida cautelar decretada por tribunales de familia, medida que no se encontraba vigente y que, por lo mismo, no podía incumplirse. En un delito de ese tipo parece que la mínima información requerida para confirmar la viabilidad de la persecución penal es precisamente el antecedente de la medida que se imputa de parte de la policía se ha incumplido. Ese mínimo deber de verificación no se cumplió en este caso y llevó a que se persiga una responsabilidad penal inexistente. Algo similar puede señalarse del caso de Diego Nieto quien es condenado por un delito que ya había sido suspendido condicionalmente por el mismo tribunal. Ambos casos sugieren que la mecanización de ciertos procesos de trabajo, especialmente en delitos menores, puede estar llevando a los actores del sistema a descuidar aspectos básicos de su función como, por ejemplo, verificar elementos mínimos de información que permitan sustentar la condena.

De la mano de lo anterior, estos casos sugieren también la existencia de problemas asociados a la calidad del trabajo de la defensa. Si llama la atención que los fiscales no hayan verificado meticulosamente que se contaba con los mínimos de información requeridos para obtener una condena, con mayor razón se esperaría que un defensor haga lo mismo antes de recomendar a su cliente admita responsabilidad. Sin tener detalles sobre cómo se llevó adelante la asesoría legal en los casos ya que no tengo esa información disponible, es claro que los defensores no impidieron

\footnotetext{
${ }^{55}$ Recordemos que en ambos casos se imputan delitos que contemplan penas privativas de libertad en abstracto que van de 541 días a 5 años (presidio y reclusión menores en su grado medio a máximo) $y$, que incluso, podrían dar lugar a tramitación del caso de conformidad a un procedimiento ordinario si es que el fiscal hubiera intentando obtener una pena superior a los 540 días de privación de libertad.
} 
que se llegara a un acuerdo en los respectivos procesos. Eso es sumamente problemático si tenían a un cliente que les señaló su inocencia.

En definitiva, aún con las limitaciones que tiene trabajar con la base de datos del recurso de revisión, esta arroja información interesante ya que muestra la existencia de condenas erróneas acreditadas con el uso de procedimientos abreviados y simplificados. Además, sugiere que los factores que inciden en esas condenas coincidirían, al menos en parte importante, con aquellos descritos por la investigación comparada. Esto obliga a mirar con un poco más de detalle las dinámicas específicas de cómo se llevan adelante estos procedimientos en forma cotidiana.

\subsubsection{Los factores y las dinámicas: hallazgos de las entrevistas y de la observa- ción de audiencias}

En esta sección presentaré los principales hallazgos que surgen de las entrevistas y de la evidencia que proviene de la observación de audiencias.

Lo primero que debo señalar es que existe un cierto consenso en los entrevistados en que en la práctica cotidiana del sistema el uso de los procedimientos abreviados y simplificados con reconocimiento de responsabilidad podría prestarse para generar condenas erróneas ${ }^{56}$. Con distintos énfasis, marcados especialmente por los diversos roles que desempeñan, se detectan inquietudes en relación al rol que cumplirían los defensores (públicos y privados) en evitar este fenómeno, la real comprensión y conocimiento que tienen los imputados al momento de aceptar que su caso se tramite de conformidad a estos procedimientos, el reconocimiento que existen incentivos perversos en todos los actores del sistema de concluir con rapidez los casos, y el hecho que cuando estos procedimientos se llevan adelante en la audiencia de control de la detención (primera audiencia) los riesgos se intensifican.

Al analizar en detalle las entrevistas por categoría de actores es posible identificar algunas diferencias y matices. Me detengo en la revisión de las percepciones de los tres actores institucionales entrevistados. Parto por los fiscales quienes destacan dos temas. Por un lado, estos señalan que podrían darse aceptaciones a estos procedimientos de personas inocentes por razones "estratégicas", es decir, que se basan en una ponderación de los beneficios que traería la negociación a la luz de los riesgos que podría significar llevar el caso a juicio ${ }^{57}$. De la mano de lo anterior, también se

\footnotetext{
${ }^{56}$ Con todo, no se trata de una opinión monolítica ya que hay quienes creen que no hay riesgos o si los hay estos son muy bajos (Fiscal N 5, comunicación personal, 4 de septiembre de 2015; Fiscal № 6, comunicación personal, 11 de septiembre de 2015; Defensor Penal Público Nº 8, comunicación personal, 11 de mayo de 2016).

${ }^{57}$ La idea que se trata de una decisión fundamentalmente estratégica se repite en muchas de los relatos recogidos en las entrevistas (Fiscal N 3, comunicación personal, 10 de julio de 2015; Fiscal N $\mathrm{N}^{\circ}$, comunicación personal, 2 de octubre de 2015; Fiscal $N^{\circ} 8$, comunicación personal, 28 de diciembre de 2015; Fiscal № 9, comunicación personal, 4 de enero de 2016 y Fiscal № 10, comunicación personal, 6 de enero de 2016). También es una idea que se repite en los abogados privados entrevistas. Así, Abogado Particular N 1, comunicación personal, 2 de junio de 2015 y Abogado Particular N 4, comunicación personal, 22 de julio de 2015).
} 
Los procedimientos abreviados y simplificados y el riesgo de condenas erróneas en Chile.

reconoce que la obtención de libertad a cambio de la aceptación de estos procedimientos podría ser otro factor que incide en la condena de inocentes ${ }^{58}$.

Los defensores públicos, por su parte, identifican como un aspecto importante del problema el bajo nivel educacional de sus "clientes habituales" (Defensor Penal Público $\mathrm{N}^{\circ} 3$, comunicación personal, 2 de julio de 2015 y Defensor Penal Público $\mathrm{N}^{\circ}$ 4, comunicación personal, 2 de julio de 2015) o, como lo plantea otro defensor, las dimensiones o aspectos culturales del problema (Defensor Penal Público № 1, comunicación personal, 11 de junio de 2015). Este factor explicaría que los imputados tengan una tendencia a sobredimensionar los riesgos que podría producir la continuación del procedimiento por vías regulares y preferir en cambio soluciones de corto plazo que les resuelvan el problema en forma inmediata. Los defensores públicos también hacen alusión al carácter estratégico que tendría esta decisión en muchos de sus clientes en términos similares a los descritos por los fiscales (Defensor Penal Público $\mathrm{N}^{\circ} 1$, comunicación personal, 11 de junio de 2015; Defensor Penal Público $\mathrm{N}^{\circ}$ 6, comunicación personal, 01 de abril de 2016 y Defensor Penal Público № 7, comunicación personal, 19 de abril de 2016). Finalmente, también se destaca la existencia de incentivos perversos como la posibilidad de quedar en prisión preventiva y la presión que pone el sistema de terminar casos en primera audiencia (Defensor Penal Público $N^{\circ}$ 3, comunicación personal, 2 de julio de 2015 y Defensor Penal Público № 4, comunicación personal, 2 de julio 2015). Sobre este último punto, las estadísticas de la Defensoría Penal Pública más recientes muestran que efectivamente un porcentaje muy significativo de casos concluye en primera audiencia y, en todo caso, en tiempos muy breves de tramitación ${ }^{59}$.

La mirada de los jueces de garantía ratifica varias de las preocupaciones expresadas por fiscales y defensores y agrega una visión crítica al trabajo de estos actores. Una primera cuestión en la que existe coincidencia con otros puntos de vista es en relación a la falta de información que perciben tienen los imputados al momento de tomar la decisión de aceptar un procedimiento abreviado o uno simplificado con reconocimiento de responsabilidad. ${ }^{60}$ Asociado con este problema estaría una crítica

\footnotetext{
${ }^{58}$ Un fiscal refiriéndose a los procedimientos abreviados señala "En casos de abreviados con penas que no son de cumplimiento efectivo, yo diría un porcentaje significativo: $1 \%$ o $2 \%$ pueden ser personas que reconocen hechos o antecedentes para que en la condena se les conceda un beneficio alternativo y la libertad...eso o prisión preventiva" (Fiscal $N^{\circ} 4$, comunicación personal, 28 de julio 2009). En una línea similar: Fiscal Nº (comunicación personal, 4 de enero de 2016) y Abogado Particular N 6 (comunicación personal, 25 de agosto de 2016).

59 Los datos disponibles de la Defensoría Penal Pública (2018) muestran que el porcentaje de casos que concluyen en primera audiencia es alto. Así, para el período enero-agosto de 2017 , el $47,1 \%$ del total de casos terminados se habría producido con una o dos audiencias. Además indican que en un $29,8 \%$ de ellos lo habría hecho en un período de menos de un mes de tramitación. Cabe señalar que la tendencia en el tiempo ha sido a disminuir el porcentaje de casos que concluyen en primera audiencia. Según datos de la Defensoría Penal Pública, el año 2008 un 54,1\% de los casos que conocieron concluyeron en dicha audiencia. (Duce Julio y Riego Ramírez, 2011, p. 141).

${ }^{60}$ Un Juez de Garantía señala "...muchas veces en la audiencia nosotros detectamos falta de información del imputado, por ejemplo, la posibilidad de decir que no, las consecuencias que eso podría tener también, entonces no hay mucha claridad..." (Juez de Garantía N³, comunicación personal, 26 de junio de 2015). Otro juez lo expresa en términos más coloquiales "Cachan muy poco los imputados...Los primerizos, la mayoría debe salir sin entender ni jota lo que pasó" (Juez de Garantía N 7, comunicación personal 14 de septiembre de 2015). Hay otros jueces que también manifiestan esta misma preocupación
} 
importante de los jueces de garantía al trabajo de los defensores en dos distintas dimensiones: deficiencias en el cumplimiento de su deber de informar adecuadamente a los clientes acerca de los alcances y consecuencias de la decisión (Juez de Garantía №3, comunicación personal, 26 de junio de 2015 ; Juez de Garantía № 5 , comunicación personal, 15 de julio de 2015 y Juez de Garantía º 7, comunicación personal, 14 de septiembre de 2015$)^{61}$ y en algunos casos derechamente una cierta presión para su aceptación ${ }^{62}$.

Los jueces también identifican la existencia de incentivos perversos del sistema para que se produzcan aceptaciones de personas potencialmente inocentes. La principal que es mencionada es la privación libertad, ya sea que el imputado evite prisión preventiva o asegure una pena de cumplimiento alternativa (Juez de Garantía $N^{\circ}$ 2, comunicación personal, 25 de junio 2015; Juez de Garantía № 4, comunicación personal, 8 de julio de 2015 y Juez de Garantía № 9, comunicación personal, 28 de julio de 2016) ${ }^{63}$. Otro incentivo perverso es identificado por un juez que pone especial énfasis en el rol que las metas de gestión de las distintas instituciones tendrían en esto (Juez de Garantía N 5, comunicación personal, 15 de julio de 2015). Además, también surgen preocupaciones por el hecho que muchos de estos procedimientos se articulen en la primera audiencia, aun cuando se reconoce en el tiempo esto ha ido en disminución (Juez de Garantía № 4, comunicación personal, 8 de julio de 2015;

Juez de Garantía N 4 (comunicación personal, 8 de julio de 2015) y Juez de Garantía Nº 5 (comunicación personal, 15 de julio de 2015).

${ }^{61}$ El Juez de Garantía № 5 pone énfasis en la insuficiencia de explicaciones más que en su inexistencia y el Juez de Garantía N 7, identifica comportamientos muy disimiles de defensores en su "vocación" por explicar con claridad al imputado estas instituciones y sus consecuencias.

${ }^{62}$ Un juez de garantía sostiene refiriéndose a los procedimientos abreviados señala que "Cuando uno escucha los audios y vez que el mismo defensor les recomienda abreviado a pesar de que lo que dicen no tiene nada que ver, es tremendo" (Juez de Garantía № 9, comunicación personal, 28 de julio de 2016). Manifestando también preocupaciones similares (Juez de Garantía №3, comunicación personal, 26 de junio de 2015; Juez de Garantía N 4, comunicación personal , 8 de julio de 2015; Juez de Garantía º 7, comunicación personal, 14 de septiembre de 2015 y Juez de Garantía N 8, comunicación personal, 4 de enero de 2016). Algunos abogados privados también hacen una crítica similar, aun cuando (Abogado Particular $\mathrm{N}^{\circ}$ 6, comunicación personal, 25 de agosto de 2016) focaliza su opinión en lo que ocurre en los procedimientos simplificados con reconocimiento de responsabilidad. Se trata también de un tema mencionado por un fiscal, (Fiscal N 1, comunicación personal, 7 de mayo de 2015). Sin llegar tan lejos un abogado privado critica que muchos de sus colegas no hagan un esfuerzo que vaya más allá de la aceptación de estos procedimientos, lo que en parte se explicaría por el desconocimiento que tienen de sus clientes y casos (Abogado Particular $N^{\circ} 1$, comunicación personal, 4 de mayo de 2015). El problema de la presión del defensor a su cliente por aceptar abreviados incluso ha llegado a la jurisprudencia de la Corte Suprema. En diciembre de 2017 la Corte rechazó un recurso de casación presentado por una persona que demandó en sede civil indemnización de perjuicios por falta de servicio de un defensor penal público, entre otras materias, debido a que fue apremiado por los "consejos" de su defensa para aceptar un procedimiento abreviado (en el que fue condenado) a pesar de haber sostenido su discrepancia con los hechos imputados. La Defensoría Penal Pública sancionó al abogado por estos hechos y la Corte consideró la existencia de una falta de servicio en los mismos. Con todo, el voto de mayoría rechazó la casación al considerar no acreditada la causalidad en los daños producidos (Viliz (Veliz) Trillo Leononel Luis con Defensoría Penal Publica, 2017).

${ }^{63}$ El Juez de Garantía N ${ }^{\circ} 2$ pone énfasis en el impacto de condenas a penas no efectivas. El Juez de Garantía $N^{\circ} 4$, enfatiza el rol de la prisión preventiva y el Juez de Garantía $N^{\circ} 9$ pone énfasis en que la persona comparezca a la audiencia privada de libertad. Se suma también la opinión de un abogado privado que pone énfasis en la situación que se produce especialmente en los procedimientos simplificados (Abogado Particular N², comunicación personal, 2 de junio de 2015).

Rev. derecho (Coquimbo, En línea) 2019, 26: e3845 
Juez de Garantía № 5, comunicación personal, 15 de julio de 2015 y Juez de Garantía $N^{\circ}$ 9, comunicación personal, 28 de julio de 2016). ${ }^{64}$.

Como se puede apreciar, con algunas diferencias de énfasis y perspectivas que provienen del rol que ocupa cada actor en el sistema, pareciera existir un nivel de reconocimiento importante de la existencia de riesgos de condenas erróneas en estos procedimientos. En términos generales estos coincidirían con los que han sido también identificados en la experiencia comparada. En lo que sigue haré un análisis un poco más detallado de tres de los hallazgos más problemáticos de la investigación.

a) ¿Ofertas atractivas de los fiscales?:

Como se revisó con anterioridad, uno de los factores centrales en el ámbito anglosajón que explica la condena de inocentes en procedimientos negociados, especialmente en los Estados Unidos, es la enorme discrecionalidad con que cuentan los fiscales que les permite formular ofertas de pena muy atractivas a los imputados. Esto genera un entorno coercitivo que incrementa los riesgos que un inocente se declare culpable. También, como se señaló con anterioridad, desde la tradición continental existe la percepción que los límites que normalmente se fijan para los casos en que se puede negociar y las facultades discrecionales más restringidas con las que cuentan los fiscales atenúan esos riesgos.

El diseño original del proceso penal nacional se hizo considerando la crítica que se formulaba al plea bargaining en los Estados Unidos y siguió la lógica de regulación de otros países de América Latina y Europa continental ${ }^{65}$. El simplificado con reconocimiento de responsabilidad, por el ámbito de penas a los que se aplica (faltas o simples delitos en los que la pena requerida no exceda de 540 días de privación de libertad), naturalmente tendría aún más salvaguardas. En este contexto, nuestros fiscales tendrían un espacio mucho menor para hacer "ofertas atractivas" a los imputados y ello debiera redundar en un riesgo bajo de condenas erróneas ${ }^{66}$.

La investigación muestra que esta idea debe ser matizada. En efecto, la experiencia de varios de los actores entrevistados es que los fiscales sí disponen en la práctica cotidiana del sistema de espacios de discrecionalidad importantes. Estos les permiten formular proposiciones de rebaja de pena significativas a los imputados que podrían constituirse en incentivos perversos para aceptar su procedencia no obstante la persona sea inocente. Un fiscal señala al respecto "Además estamos en un

\footnotetext{
${ }^{64}$ Esto es consistente con los datos de la Defensoría Penal Pública ya citados.

${ }^{65}$ Sobre esta filosofía original del Código Procesal Penal, vea Riego Ramírez (2017, pp. 1088-1090). Como el autor señaló en secciones anteriores, este diseño ha sido alterado producto de la modificación introducida por la Ley 20.931 (2016), tema que abordará más adelante.

${ }^{66}$ Se trata de un tema que tiene regulación interna en el Ministerio Público. La materia está regida por el Oficio FN n 286-2010 de 31 de mayo de 2010 (instrucción general que imparte criterios de actuación para los procedimientos especiales del libro IV del Código Procesal Penal). La instrucción general señala a los fiscales atenerse al mérito del proceso en la calificación jurídica, pena y circunstancias modificatorias que se solicitan en los simplificados y, especialmente, considerar que la pena que requieren de conformidad a la Ley 19.696 (2000, art. 3959) debe tener mérito legal. En materia de procedimientos abreviados también se insiste en la necesidad de atenerse al mérito de la investigación y no rebajar excesivamente la pena, como también respetar el principio de legalidad. Más allá de esto, se trata de párrafos bastante genéricos.
} 
nivel en que la oferta institucional de los fiscalías es cada vez más atractiva, lo que hace viable al imputado aceptar" (Fiscal № 2, comunicación personal, 9 de junio de 2015). En esta misma dirección también se pronuncia un abogado particular al señalar que, especialmente en los delitos flagrantes, tanto fiscales como defensores manifiestan niveles de flexibilidad importante en relación a las ofertas de penas, aun cuando no calcen estrictamente con lo señalado por la ley (Abogado Particular $\mathrm{N}^{\circ} 4$, comunicación personal, 22 de julio de 2015), cuestión que también es ratificada por un juez de garantía (Juez de Garantía № 2, comunicación personal, 25 de julio de 2015) ${ }^{67}$.

En este escenario, el estudio de observación de audiencias arroja resultados muy interesantes que tienden a ratificar el hallazgo descrito. En efecto, en un 100\% de los casos de abreviado y en casi un $58 \%$ de los simplificados se identificó que el fiscal realizó una rebaja de pena en el evento que el imputado manifestare su acuerdo de proceder a un procedimiento simplificado con reconocimiento de responsabilidad o a un abreviado (Zagmut Venegas, 2017, pp. 28-29). La investigación permitió también identificar los mecanismos utilizados por fiscales para ajustar las penas solicitadas. El principal fue la invocación de circunstancias atenuantes no reconocidas originalmente (típicamente la del artículo $11 \mathrm{n}^{\circ} 9$ del Código Penal referida a la colaboración sustancial con la investigación) y la eliminación de agravantes que sí habían sido consideradas. Esto se dio en un $87,5 \%$ de los abreviados y en un $52,4 \%$ de los simplificados. En segundo término, pero con un porcentaje mucho más bajo, se estableció que los fiscales modificaban circunstancias fácticas del caso (por ejemplo en un caso se eliminó que una venta de drogas se había realizado a menores de edad), cuestión que se produjo en un 12,5\% de los abreviados y sólo en un 1,6\% de los simplificados (Del Río Ferretti, 2009, pp. 81-88) ${ }^{68}$. Finalmente, sólo tratándose de simplificados, un 4,8\% de los casos hubo una alteración del grado de desarrollo del delito o iter criminis (por ejemplo se pasó de considerar el delito como consumado a frustrado) (Zagmut Venegas, 2017, pp. 29-30).

El estudio también registró otros temas de relevancia. En primer lugar, en la gran mayoría de los casos ( $80 \%$ de los abreviados y $61,9 \%$ de los simplificados) se le dio a conocer al imputado en la audiencia respectiva las diferencias de penas arriesgadas en caso de no aceptar el acuerdo (Zagmut Venegas, 2017, p. 31). Por lo tanto, el imputado pudo estar plenamente consciente de la "rebaja" de pena que le significaba aceptar el procedimiento especial ofrecido. Además, se cuantificó la magnitud de las rebajas obtenidas gracias a la aceptación de estos procedimientos especiales. En los abreviados la moda estuvo en la rebaja de un grado de la pena original. Cuando se examina en concreto la sanción específica requerida, en la gran mayoría de casos (75\%) se trata de rebajas superiores a la mitad de la pena originalmente solicitada (por ejemplo de cinco años se pasa a 541 días de privación de libertad) (Zagmut Venegas, 2017, pp. 33-35) ${ }^{69}$. Tratándose de los procedimientos simplificados, la moda

\footnotetext{
${ }^{67}$ Quien reconoce que hay dos posiciones de los jueces en la materia: quienes aplican criterios de legalidad más estrictos y quienes en cambio tienen mayor flexibilidad a favor del imputado. También habrían diferencias importantes de mayor flexibilidad en los simplificados que en los abreviados, punto en el que existe coincidencia con el abogado citado previamente.

${ }^{68}$ Se trata de un tema que ya había sido identificado como problemático por la doctrina nacional sobre la base de revisión de jurisprudencia, pero sin una cuantificación de la magnitud del problema.

${ }^{69}$ El texto citado explica con mucho mayor detalle la materia comparando las penas solicitadas y otorgadas en cada caso.
} 
también está en un grado de rebaja y en el análisis concreto en un $60 \%$ de los casos se produce una rebaja superior a la mitad de la pena original (por ejemplo se pasó de 540 a 61 días de privación de libertad, aun cuando hubo casos extremos en que se pasó de 540 a sólo una multa) (Zagmut Venegas, 2017, pp. 36-38) ${ }^{70}$.

La experiencia relatada por los actores del sistema y los datos del estudio empírico de observación de audiencias muestran que a pesar de los límites que impone nuestra legislación a la procedencia de procedimientos abreviados y simplificados, existe un espacio relevante para que los fiscales puedan hacer ofertas atractivas que podrían generar una presión o al menos incentivo fuerte para los imputados de aceptar a pesar de ser inocentes. Hay que pensar también que más allá de la pena que se solicita, parte importante de la oferta es que en casos de penas privativas de libertad de baja entidad normalmente existirá la posibilidad de obtener una pena alternativa que en la práctica se traduzca en cumplimiento en libertad de la misma. Este riesgo, además, debe ponderarse considerando el nuevo escenario normativo creado por la Ley 20.931 (2016) que amplió el margen de maniobra de los fiscales para hacer ofertas de pena sustancialmente inferiores a las que se podrían obtener en caso de no seguirse con estos procedimientos.

El impacto de esta ley no pudo ser establecido a través de las entrevistas ya que en su gran mayoría fueron realizadas antes de su entrada en vigencia. El estudio de observación de audiencias tampoco permite obtener conclusiones sobre este punto ya que su foco no fue el de observar casos cubiertos por esta ley. Con todo, el análisis normativo de la misma permite presumir sobre la posibilidad de un impacto relevante. Cómo se recordará, esta reforma introdujo una modificación al sistema de determinación de penas en contra de delitos contra la propiedad (hurtos y los diversos tipos de robos) estableciendo un nuevo art. 449 del Código Penal en virtud de la cual el juez, al determinar la pena, no puede moverse del marco penal mínimo establecido por el legislador, aun cuando el imputado cuente con diversas circunstancias modificatorias en su favor. Luego, estableció la posibilidad excepcional de rebaja en un grado de esa pena en caso de aceptarse procedimiento abreviado o simplificado (modificaciones a los art. 407 inc. 4 y art. 395, inc. 2 de Código Procesal Penal). Finalmente, amplió el margen máximo de procedencia del procedimiento abreviado en estos delitos a casos en donde se solicita hasta diez años de privación de libertad (Ley 19.696, 2000, art. 406, inc. 1).

En la práctica esto significa que si el fiscal acusa por un delito de robo con violencia calificado previsto en el Código Penal (1874, art. 433, 3), que establece como pena mínima el presidio mayor en su grado medio (10 años y un día a 15 años de privación de libertad), la única posibilidad de obtener una pena inferior en un grado sería a través de la aceptación de un procedimiento abreviado que podría reducirla hasta cinco años y un día. En un ejemplo más habitual, el robo con violencia o intimidación simple del Código Penal (1874, art. 436) que tiene prevista como mínimo el presidio mayor en su grado mínimo (de cinco años y un día a 10), se podría llegar a una pena de tres años y un día en caso de ser llevada por procedimiento abreviado.

\footnotetext{
${ }^{70} \mathrm{El}$ texto citado explica con mucho mayor detalle la materia comparando las penas solicitadas y otor-
} gadas en cada caso. 
Nuevamente una rebaja muy importante. Ejemplos similares pueden invocarse para los simplificados. Así, en el delito de robo por sorpresa del Código Penal (1874, art. 436, inc. 2), la aceptación de responsabilidad permitiría obtener una rebaja del mínimo fijado en 541 días a 61 días de presidio menor.

Los delitos cubiertos por esta reforma legal representan cerca del $40 \%$ de los ingresos del sistema y del $60 \%$ de las personas privadas de libertad en prisión preventiva (Riego Ramírez, 2017, p. 1095). Esto permite asumir que debieran representar a futuro un importante flujo de los casos que se someten a estos procedimientos negociados.

b) Defensores que tienen poca interacción con sus clientes:

Otro factor de riesgo mencionado en la experiencia comparada se asocia al trabajo de los defensores en este tipo de procedimientos. Esto se vincula a varios comportamientos posibles como no informar adecuadamente al cliente, presionarlo para llegar a un acuerdo por razones más bien de comodidad y ahorro de trabajo, recomendaciones erradas por falta de conocimiento legal, etc. Como señalé previamente, varios actores entrevistados manifiestan dudas acerca del trabajo de los defensores en nuestro país (públicos y privados). Incluso algunos de los defensores públicos entrevistados tuvieron una posición crítica sobre el punto (Defensor Penal Público $\mathrm{N}^{\circ} 3$, comunicación personal, 2 de julio de 2015 y Defensor Penal Público $\mathrm{N}^{\circ} 4$, comunicación personal, 2 de julio de 2015). Uno de los aspectos que surgió con más fuerza en las entrevistas fueron las dudas acerca del trabajo realizado por informar adecuadamente a los imputados. Esto tendría un impacto en la real voluntariedad de los mismos al momento de aceptar (entendida como una decisión tomada con conocimiento y comprensión de sus alcances), lo que es un problema en sí mismo independiente de su impacto en la condena de inocentes. Se trata de problemas que han sido reconocidos en parte por la propia Defensoría Penal Pública, la que ha venido desarrollando estándares de trabajo para sus integrantes que han puesto particular cuidado en remarcar los deberes de información para con sus clientes, especialmente en el contexto de las primeras audiencias ${ }^{71}$.

Nuevamente el estudio de observación de audiencias aporta antecedentes adicionales a las entrevistas que vale la pena revisar. Todos ellos giran en torno al nivel de interacción que existe entre imputados y sus defensores (públicos y privados) en las audiencias observadas. Debo aclarar que el estudio no pudo medir el con-

\footnotetext{
${ }^{71}$ El instrumento más reciente y específico es el Manual de Actuaciones Mínimas en Primeras Audiencias del mes de abril de 2016. Este surge en parte por el reconocimiento de la necesidad de mejorar las prácticas en el desarrollo previo, durante y con posterioridad a estas audiencias para fortalecer el ejercicio del derecho a la defensa de los imputados. En su sección 1.2 establece la obligación de desarrollar una entrevista en forma previa a la primera audiencia y en la sección 1.2.2 regula que uno de los objetivos centrales de ésta es informar al imputado respecto a sus alternativas en el proceso y desarrollar así una estrategia preliminar. En la sección 1.2.5 se refuerza esto al establecer deberes de información específicos que debe cumplir el defensor incluyendo nuevamente la situación concreta en que se encuentra el imputado y las alternativas que dispone. En la sección 8 se regulan las audiencias de procedimiento simplificado, estableciéndose deberes específicos de información en contextos en que se formule la posibilidad de admitir responsabilidad de conformidad a la Ley 19.696 (2000, art. 395), (Resolución exenta N 153, 2016).
} 
Los procedimientos abreviados y simplificados y el riesgo de condenas erróneas en Chile.

tacto que se tuvo con anterioridad a la audiencia, por lo que es necesario tener presente ese aspecto al momento de evaluar los resultados.

El estudio pudo establecer que en los procedimientos abreviados hubo un $60 \%$ de casos en donde se produjo algún tipo de interacción entre imputado y defensor en la audiencia y un $40 \%$ en que no lo hubo. En los simplificados esas cifras son de $71,4 \%$ de contacto y $28,6 \%$ en que no lo hubo. Con todo, en este último caso si se desagregan las audiencias de simplificado en aquellas que son flagrantes y las programadas se puede apreciar un panorama algo distinto. Contrario a lo que intuitivamente se podría esperar, tratándose de audiencias de reconocimiento de responsabilidad en delitos flagrantes (Ley 19.696, 2000, art. 393 bis) el porcentaje de contacto baja a un $63,3 \%$ versus el no contacto de $36,6 \%$. En las audiencias programadas sube a $78,8 \%$ de contacto y $21,2 \%$ de no contacto (Zagmut Venegas, 2017, pp. 41 43). La paradoja es que tratándose de la audiencia que se realiza con mayor premura por el sistema y en donde, por lo mismo, ha existido menos posibilidad de contacto previo entre el imputado y su defensor, la tasa sea más baja que el promedio general de los simplificados.

El estudio complementa el dato anterior e intenta evaluar la calidad de las interacciones en los casos en que si la hubo. Para ello ocupa un parámetro objetivo que es la medición del tiempo de duración de las conversaciones que tuvieron los defensores con los imputados en la audiencia. En los procedimientos abreviados en un $57,1 \%$ de los casos tuvieron una extensión de hasta 30 segundos, lo se produjo en un $64,3 \%$ de los simplificados (Zagmut Venegas, 2017, p. 46). Es decir, en la gran mayoría de las audiencias en donde hubo conversaciones, éstas fueron extremadamente breves. En el análisis realizado por la autora la mayoría de esas conversaciones tuvieron que ver con explicar el monto de la pena y no los alcances y consecuencias del procedimiento (Zagmut Venegas, 2017, pp. 47-48).

Analizando los datos en su conjunto, es posible afirmar que al menos en un tercio de los casos no existe interacción en las audiencias entre los imputados y sus defensores. En los casos en que si lo hay, en su gran mayoría se trata de un apoyo bastante incompleto para asegurar que la decisión que se adopte sea con plena comprensión de sus alcances y consecuencias. Además, se trata de un fenómeno que se repite tratándose de defensas públicas o privadas. Estamos en presencia de un hallazgo llamativo y preocupante.

Estos datos podrían considerarse menos problemáticos si es que hubiese evidencia de que el imputado tiene en la audiencia una participación autónoma relevante, es decir, que toma la palabra e interactúa con el juez sin necesidad que su intervención haya sido requerida específicamente. Los datos del estudio muestran lo contario, ya que sólo en un $2,5 \%$ de las audiencias de abreviado y en un $9,5 \%$ de las de simplificado eso se produce (Zagmut Venegas, 2017, pp. 78-79). La regla general entonces es que el imputado participa pasivamente en la audiencia, se comunica poco y brevemente con su defensor y sólo interviene cuando es requerido específicamente por el juez, por ejemplo, para responder si acepta el abreviado o el simplificado con reconocimiento de responsabilidad. 
c) Jueces de garantía que ejercen escaso control:

Un último tema en el que hago un análisis particular se refiere al trabajo de control que realizan los jueces de garantía encargados de aprobar y sentenciar los casos de procedimientos abreviados y simplificados. Como señalé en su oportunidad, la evidencia comparada identifica que la falta de control jurisdiccional a los procesos negociados es un factor que incrementa la probabilidad de condenas erróneas. Esta se podría producir por diversas razones. Por ejemplo, por problemas de comprensión de rol de los propios jueces que estiman no les corresponde "entrometerse" en las negociaciones; por la existencia de incentivos perversos que llevan a que se privilegie el interés de procesar rápido estos casos; por problemas de conocimiento y capacitación de los jueces en cómo hacer esos controles; entre otras.

Las entrevistas entregan algunas luces sobre esta materia. Lo primero que debo señalar es que existe una visión discrepante entre los diversos actores entrevistados acerca de la calidad e intensidad con la que se hace el control por parte de los jueces. Así, hay un grupo no despreciable de entrevistados que estima que el trabajo judicial es adecuado (Fiscal № 6, comunicación personal, 11 de septiembre de 2017; Fiscal № 12, comunicación personal, 12 de enero 2016 y Juez de Garantía № 3, comunicación personal, 26 de junio de 2015) y que ello ocurre especialmente tratándose del procedimiento abreviado, derivado de las consecuencias más graves que éste trae aparejadas para el imputado (Juez de Garantía $N^{\circ}$ 7, comunicación personal, 14 de septiembre de 2017 y Abogado Particular N², comunicación personal, 2 de junio de 2015). Con todo, hay otro grupo que estima más problemático la forma en que se cumple este rol. Entre ellos se encuentran defensores públicos (Defensor Penal Público $\mathrm{N}^{\circ} 2$, comunicación personal, 17 de junio de 2015; Defensor Penal Público $\mathrm{N}^{\circ} 3$, comunicación personal, 02 de julio de 2015 y Defensor Penal Público № 4, comunicación personal, 02 de julio de 2015) y privados (Abogado Particular N² 2, comunicación personal, 02 de junio de 2015 y Abogado Particular $N^{\circ}$ 6, comunicación particu-

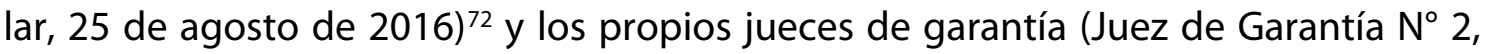
comunicación personal, 25 de junio de 2015; Juez de Garantía N³ 3, comunicación personal, 26 de junio de 2015; Juez de Garantía № 5, comunicación personal, 15 de julio de 2015 y Juez de Garantía № 7, comunicación personal, 14 de septiembre de $2015)^{73}$. Los temas que se plantean en esta visión más crítica son tres. Una es la identificación de las metas de gestión como un riesgo que le pone presión a los jueces (como también a otros actores) para terminar los casos rápido y ello llevaría a que relajen los controles que la ley obliga realizar a la procedencia de ambos procedimientos (Defensor Penal Público N³ 3, comunicación personal, 2 de julio de 2015; Defensor Penal Público $N^{\circ}$ 4, comunicación personal, 2 de julio de 2015 y Juez de Garantía № 5, comunicación personal, 15 de julio de 2015). Otro problema estaría más bien al momento de sentenciar el caso en base a estos procedimientos. Así, se critica por varios actores que la aceptación o reconocimiento de responsabilidad llevaría a una condena automática con escaso o nulo análisis del caso, lo que abriría a riesgos de condenas erróneas (Defensor Penal Público N² 2, comunicación personal,

\footnotetext{
${ }^{72}$ Abogado Particular $\mathrm{N}^{\circ} 2$ pone foco en materia de procedimientos simplificados.

73 Juez de Garantía №3 también referido centralmente a los simplificados. 
17 de junio de 2015 y Abogado Particular N² 2, comunicación personal, 25 de agosto de 2016). Finalmente, pareciera existir también un problema de comprensión de rol por el trabajo de control más intenso a los procesos negociados. Por ejemplo, un juez de garantía, refiriéndose a las aceptaciones de responsabilidad en los procedimientos simplificados, señala que "...no debiéramos meternos en los antecedentes..." (Juez de Garantía N 3, comunicación personal, 26 de junio de 2015) para corroborar la aceptación, como sí lo hace en el abreviado, al considerar que no les corresponde hacerlo. Otros jueces, en cambio, constatan que en la práctica muchos colegas no hacen el trabajo de preguntar intensamente al imputado sobre su voluntariedad y lo explican como un tema de "falta de vocación" (Juez de Garantía № 7, comunicación personal, 14 de septiembre de 2015) o simplemente lo constatan sin explicar mucho su causa (Juez de Garantía N² 2, comunicación personal, 25 de junio de 2015).

No es posible obtener conclusiones muy definitivas a partir de estos relatos, por eso es interesante examinar los resultados de la investigación basada en la observación de audiencias ya que entrega alguna evidencia complementaria. En esta investigación se intentó determinar, a partir de algunos indicadores específicos, el nivel de control jurisdiccional sobre estos procedimientos.

El primer indicador midió si los jueces verificaban, preguntándole al imputado, si habían sido informados previamente por su abogado defensor acerca de los alcances y consecuencias al aceptar estos procedimientos especiales. La respuesta es que sólo en un $17,5 \%$ de los abreviados y un $6,3 \%$ de los simplificados ello ocurría, es decir, en un porcentaje muy menor del total de casos observados (Zagmut Venegas, 2017, p. 57). Un segundo indicador, complementario al anterior, era identificar si el juez brindaba alguna explicación al imputado (no importando lo precaria que esta fuera) acerca del procedimiento que se le estaba ofreciendo y sus consecuencias. Los resultados muestran que los jueces hicieron esto en un 52,5\% de los abreviados y en un $38,1 \%$ de los simplificados (Zagmut Venegas, 2017, pp. 58) ${ }^{74}$. Un tercer indicador del estudio fue determinar si los jueces realizaban alguna pregunta a los imputados destinada a verificar su entendimiento y voluntariedad para proceder conforme a estos procedimientos. En materia de entendimiento el resultado arroja que en $50 \%$ de los abreviados y en un $19 \%$ de los simplificados hubo alguna verificación de parte del juez (Zagmut Venegas, 2017, pp. 65-69) ${ }^{75}$. Tratándose de la voluntariedad, lo que se midió fue si los jueces advertían al imputado la necesidad que su aceptación fuera de esa naturaleza, no importando la forma o contenido de dicha advertencia en la medida que se le dijera que la aceptación tenía que ser voluntaria. El resultado fue que en un $22,5 \%$ de los abreviados y un $14,3 \%$ de los simplificados hubiera alguna advertencia de este tipo (Zagmut Venegas, 2017, p. 70). También se midió si los jueces efectivamente verificaban el acuerdo del imputado fuera voluntario. Esta labor se hizo en un $33,3 \%$ de los abreviados y sólo en un $6,8 \%$ de los simplificados (Zagmut

\footnotetext{
${ }^{74}$ El estudio también hace un análisis de la calidad o suficiencia de las explicaciones de los jueces concluyendo que en un $52,4 \%$ de los abreviados estas son insuficientes y lo mismo en un $70,8 \%$ de los simplificados. Un análisis detallado de los criterios para distinguir las explicaciones, así como también de muchos ejemplos en: (Zagmut Venegas, 2017, pp. 59-65).

${ }^{75} \mathrm{Al}$ igual que en el indicador anterior, la autora también hace un esfuerzo por determinar si estas verificaciones fueron realizadas a través de preguntas más bien formales o verdaderamente de control. El resultado fue que el $60 \%$ de los abreviados y el $83,3 \%$ de los simplificados cuando hubo verificación de entendimiento del imputado esto se realizó por medio de preguntas de corte formal.
} 
Venegas, 2017, p. 70). La tabla 7 presenta en forma resumida estos resultados para ayudar a su comprensión.

Tabla 7: Indicadores de comportamiento judicial en abreviados y simplificados

\begin{tabular}{|l|c|c|} 
& Abreviados & \multicolumn{1}{|c|}{ Simplificados } \\
\hline Juez verifica que imputado fue informado por defensor & $17,5 \%$ & $6,3 \%$ \\
\cline { 2 - 3 } Juez explica al imputado sobre los procedimientos & $52,5 \%$ & $38,1 \%$ \\
\cline { 2 - 3 } Juez verifica entendimiento del imputado & $50 \%$ & $19 \%$ \\
\cline { 2 - 3 } Juez advierte sobre voluntariedad de aceptación & $22,5 \%$ & $14,3 \%$ \\
\hline Juez verifica que aceptación es voluntaria & $33,3 \%$ & $6,8 \%$ \\
\hline
\end{tabular}

Fuente: elaboración propia sobre la base de Zagmut Venegas (2017, p. 57-73).

Analizados todos estos datos en conjunto, ellos muestran que la tendencia mayoritaria respecto al comportamiento judicial en estos procedimientos sería más bien pasiva, es decir, en la que los jueces no tienen un rol muy activo asegurándose que se le haya explicado adecuadamente al imputado los alcances y consecuencia de estos procedimientos ni tampoco ellos emprendido tal tarea. Por otra parte, la actividad destinada a verificar la comprensión y voluntariedad del acuerdo que han prestado los imputados también es baja. Existe eso si una clara diferencia entre los abreviados y simplificados, ya que en estos últimos las cifras serían significativamente más bajas, lo que coincide con la experiencia de los actores al señalar que por la gravedad de las consecuencias, normalmente el abreviado es objeto de mayor escrutinio de parte de los jueces.

Sin poder llegar a conclusiones muy definitivas en la materia, los datos expuestos muestran que en nuestra práctica cotidiana en las audiencias de estos procedimientos también se daría un espacio de trabajo sujeto a niveles bajos de control judicial que podría traducirse en un porcentaje relevante de aceptaciones de hechos y de responsabilidad de personas inocentes que luego se traducen en condenas. En todo caso, también existiría un serio riesgo de aceptaciones sin una real voluntariedad (con conocimiento y comprensión) ${ }^{76}$.

\section{Conclusiones}

La suma de los resultados expuestos sugiere que en nuestro país se presentarían factores y dinámicas similares a las descritas en la experiencia comparada que aumentan el riesgo de condenas erróneas por el uso de procedimientos como el abreviado y simplificado con reconocimiento de responsabilidad. Por lo tanto, no

\footnotetext{
${ }^{76}$ Un dato adicional que tiende a ratificar el escenario descrito es el de la duración promedio de las audiencias de juicio oral simplificado. Según datos del Poder Judicial publicados por CEJA el año 2014 habría sido de 13,5 minutos. Para valorar esto debe considerarse que ese promedio incluye casos en los que efectivamente el juicio fue llevado adelante y eso aumenta el promedio real de los casos en los que sólo hubo reconocimiento de responsabilidad. (Fandiño Castro, Rua, Moreno Holman y Fibla Cerda, 2017, p. 300).
} 
sería de extrañar que tengamos un problema más profundo que el que hasta el momento conocemos. Más allá de esto, también mostrarían que hay algunos problemas graves para el cumplimiento de uno de los supuestos básicos que legitima a estos procedimientos como lo es la existencia de una voluntariedad real en la aceptación de su procedencia de parte del imputado. Ambas cuestiones son muy preocupantes.

Es cierto que los sistemas de justicia penal suelen presentar limitaciones estructurales para el esclarecimiento de la verdad y, además, para procesar de manera más sofisticada a la enorme masa de casos que ingresan, por ejemplo, con un alto porcentaje de casos que sean resueltos en juicio oral. Esto hace que, por más duro que sea admitirlo, la posibilidad de error es una realidad con la que es necesario convivir. Tampoco parece probable que en el corto plazo lleguemos a un nivel de desarrollo que haga posible prescindir del todo de procedimientos consensuales basados en la negociación como ocurre con el abreviado y el simplificado con reconocimiento de responsabilidad. Plantear entonces soluciones simples como eliminar el art. 395 del Código Procesal Penal o el procedimiento abreviado no parece realista ni tampoco conveniente a la luz de la forma en que actualmente nuestro sistema procesal penal funciona. Por si fuera poco, la tendencia manifestada por el legislador en la reforma de la Ley 20.931 (2016) ha sido más bien la de ampliar su margen de utilización (vgr. aumento de cinco a diez años de privación de libertad en ciertos delitos para la procedencia del abreviado, entre otras), aumentando así los riesgos que he descrito previamente.

En este escenario, si me parece esperable y razonable desarrollar algunas medidas que nos permitan lidiar de mejor forma con los riesgos de condenas erróneas y aceptaciones no voluntarias que genera el uso de estos procedimientos. Más que eliminar del todo, pareciera razonable prevenir y reducir su producción. Se trata de un tema complejo y que no es posible de ser desarrollado en forma extensiva en un trabajo como este cuyo propósito principal ha sido aportar en la construcción de un primer diagnóstico de la realidad nacional. Espero, no obstante lo anterior, que los resultados expuestos motiven una reflexión sobre la materia y el desarrollo de nuevos estudios empíricos que nos permitan profundizar en los hallazgos.

\section{Agradecimientos}

Este trabajo ha sido elaborado en el marco del proyecto FONDECYT Regular No 1150073 "Errores de la justicia penal: investigación empírica y dogmática sobre sus causas en nuestro país y recomendaciones para evitarlos". Agradezco la contribución de Ricardo Lillo, ayudante del proyecto, en el desarrollo de la investigación y edición final del texto. 


\section{Referencias Bibliográficas}

Albrecht H. (2001). Settlements out of court: a comparative study of European criminal justice systems. Pretoria: South African Law Commission. Recuperado de https://bit.ly/2CwvSWw

Anitúa, G. (2001). El juicio penal abreviado como una de las reformas penales de inspiración estadounidense que posibilitan la expansión punitiva. En: J. Maier y A. Bovino (Comps.). El Procedimiento abreviado (pp. 137-160). Buenos Aires: Del Puerto.

Anitúa, G. (2017). Jueces fiscales y defensores. Buenos Aires: Didot.

Fandiño Castro, M., Rua, G., Moreno Holman, L. y Fibla Cerda, G. (2007). Desafíos de la reforma procesal penal en Chile: análisis retrospectivo a más de una década. Santiago: Centro de estudios de justicia de las américas. Recuperado de https://bit.ly/33DCiiU

Bach, A. (2009). Ordinary injustice: how America holds court. New York, NY: Holt Paperbacks.

Belloni, F, y Hodgson, J. (2000). Criminal injustice. London: Palgrave.

Benner, L. (2012). Expanding the right to effective counsel at plea bargaining: opening the Pandora's box?. ABA Criminal justice, 4(27), 4-11.

Blume, J. y Helm, R. (2014). The unexonerated: factually innocent defendants who plead guilty. Cornell law review, 100(1), 157-191. Recuperado de https://bit.ly/2p8jRnq

Bibas, S. (2014). Plea bargaining's role in wrongful convictions. En A. Redlich, J. Acker, R. Norris y C. Bonventre (Eds.). Examining wrongful convictions: stepping back, moving forward (pp. 157-168). Durham: Carolina Academic.

Bovino, A. (1997). La persecución penal pública en el derecho anglosajón, Pena y Estado. Revista latinoamericana de política criminal, (2), 35-79. Recuperado de https://bit.ly/2WVMMaK

Broackman, J. (2010). An offer you can't refuse: pleading guilty when you are innocent. Criminal law quaterly, 56(1-2), 116-134.

Bustamante Cruz María Angélica con Fisco de Chile, 233-2017 (Corte Suprema 5 de diciembre de 2017). Recuperado de https://bit.ly/2CD3tOT

Cerda San Martín, R. (2016). Segunda agenda corta antidelincuencia $n^{\circ} 20.931$. Santiago: Librotecnia.

Contra Diego Nieto Vásquez, 2227-2011 (Corte Suprema 24 de mayo de 2011). Recuperado de https://bit.ly/352Fbdo

Contra Víctor Raúl Moreno Delgado, 4308-2013 (Corte Suprema 22 de agosto de 2013). Recuperado de https://bit.ly/2QhHN2S

Chile, Ministerio de Justicia. (1874). Código Penal. Recuperado de http://bcn.cl/1uvs0 Rev. derecho (Coquimbo, En línea) 2019, 26: e3845 
Los procedimientos abreviados y simplificados y el riesgo de condenas erróneas en Chile.

Defensoría Penal Pública. (2018). Anexo. Tablas informe estadístico: enero a diciembre 2017(XLSX). Recuperado de https://bit.ly/33KcMIM

Díaz Cantón, F. (2001). Juicio abreviado vs. Estado de derecho. En: J. Maier y A. Bovino (Comps.). El Procedimiento abreviado (pp. 251-276). Buenos Aires: Del Puerto.

Del Río Ferretti, C. (2009). Proceso penal consenso de las partes y enjuiciamiento jurisdiccional. Santiago: Librotecnia.

Resolución exenta $\mathrm{N}^{\circ} 153$, establece manual de actuaciones mínimas en primeras audiencias. Defensoría penal pública, Ministerio de Justicia, República de Chile, Santiago, Chile, 13 de abril de 2016. Recuperado de https://bit.ly/2NUfZig

Dervan, L. y Edkins, V. (2012). The innocent defendant's dilemma: an innovative empirical study of plea bargaining innocence problem. Journal of criminal law and criminology, 103(1), 1-48. Recuperado de https://bit.ly/2pNsTXI

Dressler, J. y Michaels, A. (2015). Criminal procedure. Adjudication (4a ed., Vol. 2). Newark, NJ: LexisNexis.

Dripps, D. (2016). Guilt innocent and due process of plea bargaining. William and Mery law review, 57(4), 1343-1393. Recuperado de https://bit.ly/2pWEraD

Duce Julio, M. y Riego Ramírez, C. (2011). La prisión preventiva en Chile: análisis de los cambios legales y su impacto. Santiago: Ediciones Universidad Diego Portales.

Duce Julio, M. (2013). ¿Debiéramos preocuparnos de la condena de inocentes en Chile? Antecedentes comparados y locales para el debate. lus et praxis, 19(1), 77138. https://doi.org/10.4067/S0718-00122013000100004.

Duce Julio, M. (2015). Algunas lecciones a partir de cuatro casos de condena de inocentes en Chile. Revista de derecho (Coquimbo. En línea), 22(1), 149208. https://doi.org/10.4067/S0718-97532015000100005.

Duce Julio, M. (2015 b). La condena de inocentes en Chile: una aproximación empírica a partir de los resultados de los recursos de revisión acogidos por la corte suprema en el período 2007-2013. Política criminal, 10(19), 159191. https://doi.org/10.4067/S0718-33992015000100006.

Duce Julio, M. (2017). Los recursos de revisión y la condena de inocentes en Chile: Una aproximación empírica en el período 2007-2016. Doctrina y jurisprudencia penal, (30), 3-40.

Fair Trials. (27 de Abril de 2017). The Disappearing Trial Report. Recuperado de https://bit.ly/2CISqnp

Fair Trials. (24 de Marzo de 2018). Flavia Totoro. Recuperado de https://bit.ly/33QCNWW

Feeley, M. (1992). The process is the punishment. Handling cases in a lower criminal court. New York, NY: Russel Sage Foundation 
Ferrajoli, L. (2001). Las lesiones legales del modelo constitucional del proceso penal. En J. Maier y A. Bovino (Comps.). El Procedimiento abreviado (pp. 31-50). Buenos Aires: Del Puerto.

Fischer, G. (2004). Plea bargaining's triumph: a history of plea bargaining in America. Stanford, CA: Stanford University Press.

Garner, B. (Ed.). (2014). Blacks law dictionary (10a ed.). St. Paul, MN: Thomson Reuters.

Gilliéron, G. (2013). The risks of summary proceedings plea bargaining and penal orders in producing wrongful convictions in U.S. and Europe. En R. Huff y M. Killias (Eds.). Wrongful convictions and miscarriages of justice: causes and remedies in north american and european criminal justice systems (pp. 237-260). New York, NY: Routledge.

Gilliéron, G. (2013b). Wrongful convictions in Switzerland: a problem of summary proceedings. University of Cincinnati law review, 80(4), 1145-1165. Recuperado de https://bit.ly/32BqNa1

Gross, S. (2008). Convicting the inocent. Annual review of law and social science, 4, 173-192. https://doi.org/10.1146/annurev.lawsocsci.4.110707.172300.

Gross, S., y Shaffer, M. (2012). Exonerations in United States, 1989-2012. National registry of exonerations. Recuperado de https://bit.ly/2K715nD

Horne, J. (2013). Plea bargains, guilty pleas and the consequences for appeal in England and Wales. SSRN Electronic journal, (10). https://doi.org/10.2139/ssrn.2286681.

Horne, J. (2016). A plea of convenience: an examination of the guilty plea in England \& Wales (PhD thesis). University of Warwick. Recuperado de https://bit.ly/2qJSJLF

Horvitz Lennon, M. y López Masle, J. (2005). Derecho procesal penal chileno (Vol. 2). Santiago: Editorial jurídica de Chile.

Innocence Project. (2018). guiltypleaproblem.org. Recuperado de https://www.guiltypleaproblem.org/

Kasin, S. (2005). On the psychology of confessions: does innocence put innocents at risks?. American psychologist, 60(39), 215-228.

Killias, M. (2010). Wrongful convictions in Switzerland. En R. Huff y M. Killias (Eds.). Wrongful convictions: international perspectives on miscarriages of justice (pp. 139-156). Philadelphia: Temple University Press.

Killias, M. (2013). Errors occur everywhere-but not at the same frequency. En R. Huff y M. Killias (Eds.). Wrongful convictions and miscarriages of justice: causes and remedies in north american and european criminal justice systems (pp. 61-76). New York, NY: Routledge.

King, J. (2013). Beyond "life and liberty": the evolving right to counsel. Harvard civil rights-civil liberties law review, 48(1), 1-48. Recuperado de https://bit.ly/2CHYrRj 
Los procedimientos abreviados y simplificados y el riesgo de condenas erróneas en Chile.

Langbein, J. (2001). Tortura y plea bargaining. En J. Maier y A. Bovino (Comps.). El Procedimiento abreviado (pp. 3-29). Buenos Aires: Del Puerto.

Leo, R. (2009). Police interrogation and american justice. Cambridge: Harvard University Press.

Ley 18.290, de 27 de diciembre de 2007, Fija texto refundido, coordinado y sistematizado de la Ley de Tránsito, Diario Oficial de la República de Chile, Santiago, 29 de octubre de 2009. Recuperado de http://bcn.cl/1 uv0o

Ley 19.640, de 08 de octubre de 1999, Establece La Ley Orgánica Constitucional del Ministerio Publico, Diario Oficial de la República de Chile, Santiago, 15 de octubre de 1999. Recuperado de http://bcn.cl/1 uw6p

Ley 19.696, de 29 de septiembre de 2000, Establece Código Procesal Penal, Diario Oficial de la República de Chile, Santiago, 12 de octubre de 2000. Recuperado de http://bcn.cl/1uvvn

Ley 19.789, de 23 de enero 2002, Introduce modificaciones al Código Procesal Penal, Diario Oficial de la República de Chile, Santiago, 30 de enero de 2002. Recuperado de http://bcn.cl/1vb67

Ley 20.066, de 22 de septiembre de 2005, Establece Ley de Violencia Intrafamiliar. Diario Oficial de la República de Chile, Santiago, 07 de octubre de 2005. Recuperado de http://bcn.cl/1ux4l

Ley 20.074, de 09 de noviembre de 2005, Modifica Los Códigos Procesal Penal y Penal, Diario Oficial de la República de Chile, Santiago, 14 de noviembre de 2005. Recuperado de http://bcn.cl/1vrOu

Ley 20.931, de 24 de junio de 2016, Facilita la aplicación efectiva de las penas establecidas para los delitos de robo, hurto y receptación y mejora la persecución penal en dichos delitos. Diario Oficial de la República de Chile, Santiago, 05 de julio de 2016. Recuperado de http://bcn.cl/1wg75

McConville, M. y Marsh, L. (2014). Criminal judges. Cheltenham: Edward Elgar.

Medwed, D. (2012). Prosecution complex: America's race to convict and its impact on the innocent. New York, NY: New York University Press.

Ministerio Público. (2010). Oficio FN (286/2010). Recuperado de https://bit.ly/2ObznHF

Naughton, M. (2013). The innocent and the criminal justice system. London: Palgrave Macmillan.

Natapoff, A. (2012). Misdemeanors. Southern California law review. 85(5), 101-163. Recuperado de https://bit.ly/2Q7YUDV 
The National Registry of Exonerations. (4 de febrero de 2014). Exonerations in 2013. Recuperado de https://bit.ly/2CHyt08

The National Registry of Exonerations. (3 de febrero de 2016). Exonerations in 2015. Recuperado de https://bit.ly/2O8izRR

The National Registry of Exonerations. (7 de marzo de 2017) Exonerations in 2016. Recuperado de https://bit.ly/33Med9t

United States Sentencing Commission. (1 de marzo de 2018). Sourcebook 2016. Recuperado de https://bit.ly/34ZnnQi

Palma Bustos, Felicinda con Fisco de Chile, 39764-2017 (Corte Suprema 26 de diciembre de 2017). Recuperado de https://bit.ly/2KglkOr

Ried Undurraga, I. (2017). El efecto de la sentencia condenatoria del procedimiento abreviado en el juicio indemnizatorio por responsabilidad civil ex delicto. lus et praxis, 23(1), 579-626. http://dx.doi.org/10.4067/S0718-00122017000100016.

Riego Ramírez, C. (2000). El procedimiento abreviado. En A. Carocca Pérez, A. Baytelman Aronowsky, M. Duce Julio, C. Riego Ramírez y J. Vargas Vivanco. (2015). Nuevo proceso penal (pp. 205-226). Santiago: Jurídica Conosur.

Riego Ramírez, C. (2017). El procedimiento abreviado en la ley 20.931. Política Criminal, 12(24), 1085-1105. https://doi.org/10.4067/S0718-33992017000201085.

Roach, K. (2010). Wrongful convictions: adversarial and inquisitorial themes. North Carolina journal of international law and commercial regulation, 35(2), 387-446. Recuperado de https://bit.ly/2NCjDy1

Roberts, J. (2011). Why misdemeanors matter: defining effective advocacy in lower criminal courts. University of California Davis law review, 45, 277-372. Recuperado de https://bit.ly/2rC5FE9

Russano, M., Meissner, C., Narchet, F. y Kassin, S. (2005). Investigating true and false confessions within a novel experimental paradigm. Psychological science, 16(6), 481486. https://doi.org/10.1111/j.0956-7976.2005.01560.x.

Salas Astrain, J. (2015). Problemas del proceso penal. Santiago: Librotecnia.

Schauffler, R., LaFountain, R., Strickland, S., Holt, K., \& Genthon, K. (Eds.). (11 de enero de 2017). Court statistics project data viewer. Recuperado de https://bit.ly/2Xmz0yd

Thaman, S. (2010). World plea bargaining: consensual procedures and the avoidance of the full criminal trial. Durhan: Carolina Academic Press.

University of California Irvine y University of Michigan. (2012). The National Registry of Exonerations. Recuperado de https://bit.ly/2QgZAHq

Viliz (Veliz) Trillo Leononel Luis con Defensoría Penal Pública, 10438-2017 (Corte Suprema 5 de diciembre de 2017). Recuperado de https://bit.ly/2qPAbK7 
Los procedimientos abreviados y simplificados y el riesgo de condenas erróneas en Chile.

Zagmut Venegas, V. (2017). Procedimiento abreviado y simplificado en la práctica de audiencias chilenas ¿Alguna vinculación con la condena de inocentes? (Tesis de Magíster). Universidad Diego Portales.

\section{Para citar este artículo bajo Norma APA 6a ed. \\ Duce Julio, M. (2019 Los procedimientos abreviados y simplificados y el riesgo de condenas erróneas en Chile. Revista de Derecho (Coquimbo. En línea), 26, e3845, https://doi.org/10.22199/issn.0718-9753-2019-0012}

Copyright del articulo: @2019 Mauricio Duce 